\title{
Potential Mechanisms Underlying Intercortical Signal Regulation via Cholinergic Neuromodulators
}

\author{
Jung H. Lee, ${ }^{1}$ Miles A. Whittington, ${ }^{2}$ and Nancy J. Kopell ${ }^{1}$ \\ ${ }^{1}$ Department of Mathematics and Statistics, Boston University, Boston, Massachusetts 02215, and ${ }^{2}$ The Hull York Medical School University of York, \\ Heslington, York Y010 5DD, United Kingdom
}

The dynamical behavior of the cortex is extremely complex, with different areas and even different layers of a cortical column displaying different temporal patterns. A major open question is how the signals from different layers and different brain regions are coordinated in a flexible manner to support function. Here, we considered interactions between primary auditory cortex and adjacent association cortex. Using a biophysically based model, we show how top-down signals in the beta and gamma regimes can interact with a bottom-up gamma rhythm to provide regulation of signals between the cortical areas and among layers. The flow of signals depends on cholinergic modulation: with only glutamatergic drive, we show that top-down gamma rhythms may block sensory signals. In the presence of cholinergic drive, top-down beta rhythms can lift this blockade and allow signals to flow reciprocally between primary sensory and parietal cortex.

Key words: cholinergic modulation; computational model; cortical rhythms; dynamical regulation; intercortical communication

\section{Significance Statement}

Flexible coordination of multiple cortical areas is critical for complex cognitive functions, but how this is accomplished is not understood. Using computational models, we studied the interactions between primary auditory cortex (A1) and association cortex (Par2). Our model is capable of replicating interaction patterns observed in vitro and the simulations predict that the coordination between top-down gamma and beta rhythms is central to the gating process regulating bottom-up sensory signaling projected from A1 to Par2 and that cholinergic modulation allows this coordination to occur.

\section{Introduction}

Brain rhythms are believed to be involved in the flow of signals around the cortex (Fries, 2005, 2009; Buschman and Miller, 2007; Saalmann et al., 2007; Pesaran et al., 2008; Wang, 2010; Akam and Kullmann, 2012; Bosman et al., 2012). They are also well known to be associated with multiple cognitive functions (Singer and Gray, 1995; Fries et al., 2001; Womelsdorf et al., 2007; Meltzer et al., 2008; Donner et al., 2009; Chalk et al., 2010; Ghitza, 2012; Saalmann et al., 2012). However, it is far from understood how brain rhythms facilitate such function. Here, we present biophysical modeling to suggest how brain rhythms may help to coordinate and route signals among cortical layers and cortical regions. We also show that the routing of signals can be modulated by cholinergic drive. The model

Received Feb. 15, 2015; revised Sept. 24, 2015; accepted 0ct. 6, 2015.

Author contributions: J.H.L., M.A.W., and N.J.K. designed research; J.H.L. performed research; J.H.L. and N.J.K. analyzed data; J.H.L., M.A.W., and N.J.K. wrote the paper.

N.J.K. and J.H.L. were partially supported by the National Science Foundation (Grants DMS-1042134 and DMS1225647) and the National Institutes of Health-National Institute of Neurological Disorders and Stroke (Grant 5R01NS067199).

The authors declare no competing financial interests.

Correspondence should be addressed to Jung H. Lee, Allen Institute for Brain Science, 551 North 34th Street \#200, Seattle, WA 98103. E-mail: giscard88@gmail.com.

DOI:10.1523/JNEUROSCI.0629-15.2015

Copyright $\odot 2015$ the authors $\quad 0270-6474 / 15 / 3515000-15 \$ 15.00 / 0$ is inspired by in vitro data (Roopun et al., 2010). However, the main aim is to illuminate potential mechanisms for in vivo regulation.

The relevant in vitro data were produced by Roopun et al. (2010), who studied dynamics in a rodent slice consisting of primary auditory cortex (A1) and secondary somatosensory cortex (Par2), an association cortex. The investigators showed that, in the presence of glutamate drive (kainate receptor agonism), these regions were capable of producing gamma rhythms in the superficial layers of both and beta rhythms in the deep layer Par2; measurements of Granger causality (GC) showed that, in this modulatory condition, there was top-town GC in the superficial layers mediated by gamma oscillations. When cholinergic neuromodulation was added, A1 produced a cholinergically dependent beta rhythm in the deep layers and GC changes, and there was then mutual interaction in the superficial layers mediated by gamma rhythms and top-down GC in the deep layers mediated by the beta rhythm. The model described here replicates those data and suggests in vivo implications.

A critical role in the interaction between primary sensory and association cortices is played by so called low-threshold-spiking (LTS) cells of A1, which are modulated by nicotine (Xiang, Huguenard, and Prince, 1998; Roopun et al., 2010). With only glutamatergic drive, we show that top-down gamma signals may block sensory signals. In the presence of cholinergic drive, top-down beta signals 
can lift the blockade and allow signals to flow from primary sensory to association cortex; indeed, the model shows that there is an alternation between top-down and bottom-up signals between superficial layers of sensory and association cortex. Therefore, the topdown gamma and beta rhythms allow a dynamic regulation of bottom-up signals from A1 to Par2.

\section{Materials and Methods}

Models. We constructed computational models of two cortical areas, A1 and Par2, each of which has three laminar layers, the superficial (L2/3), granular (L4), and deep (L5) layers (see Fig. 1A), as described previously (Lee et al., 2013). Our model includes nine layer-specific cell types, including slowinhibitory (SI) interneurons modeling LTS cells in terms of the kinetics of their postsynaptic inhibition. L5 pyramidal cells were modeled with three compartments and all other cells were modeled with a single compartment, as in Lee et al. (2013). Al and Par2 have similar structures, but we introduced differences in their deep layers due to differential beta rhythm generation (Kramer et al., 2008; Roopun et al., 2010). In particular, we removed inhibitory projections from L5 SI cells to L5 intrinsically bursting (IB) cells and connected IB cell axons with gap junctions to model beta rhythm generation in Par2.

Dynamics of neurons in our model were calculated by voltage-gated conductance equations as follows:

$$
\begin{aligned}
& C \frac{d V}{d t}=-g_{L}\left(V-E_{L}\right)-g_{N a F} m_{0}^{3} h\left(V-E_{N a F}\right)-g_{K D R} m_{K D R}^{2} \\
& \times\left(V-E_{K D R}\right)-g_{C a H} m_{C a H}^{2}\left(V-E_{C a H}\right)-g_{C a L} m_{C a L}^{2} h_{C a L}^{2}\left(V-E_{C a L}\right) \\
& \quad-g_{M} m_{M}\left(V-E_{M}\right)-I_{s y n}-I_{a p p}-g_{e x t} \sum_{k} H\left(t-t_{0, k}\right) e^{-\left[\frac{\left(t-t_{0, k}\right)}{2}\right]} V
\end{aligned}
$$

where $E_{L}=-67 \mathrm{mV}, E_{\mathrm{NaF}}=50 \mathrm{mV}, E_{\mathrm{KDR}}=-95 \mathrm{mV}, E_{\mathrm{CaH}, \mathrm{CaL}}=125$ $\mathrm{mV}$, and $E_{M}=-95 \mathrm{mV}$; the last term represents Poisson trains of EPSCs; $H(t)$ is the Heaviside step function; and $t_{0, k}$ are the arrival times of trains of EPSCs.

The gating variables $m$ and $h$ regulating ion currents follow the Hodgkin-Huxley-type equations as follows:

$$
\frac{d x}{d t}=\alpha(1-x)-\beta x,
$$

where $\alpha$ and $\beta$ are forward and backward rate functions, respectively.

With the relationships between forward and backward rate functions and steady-state variables as follows:

$$
x_{\infty}=\frac{\alpha}{\alpha+\beta}, \quad \tau_{\infty}=\frac{1}{\alpha+\beta}
$$

Equation 2 can be described with steady-state variable as follows:

$$
\frac{d x}{d t}=\frac{1}{\tau}\left(x_{\infty}-x\right)
$$

We adopted steady-state variables for $\mathrm{NaF}, \mathrm{KDR}$, and $\mathrm{CaH}$ currents from Kramer et al. (2008), as summarized in Table 1. Not all of these currents are in all cell types (see Table 2).

The gating variables describing synaptic inputs in our model evolve according to the differential equation as follows:

$$
\frac{d s}{d t}=-\frac{s}{\tau_{d}}+\frac{1-s}{\tau_{r}}\left[1+\tanh \left(\frac{V_{p r e}}{10}\right)\right]
$$

where rise time $\left(\tau_{r}\right)$ and decay time $\left(\tau_{d}\right)$ of synapses are shown in Table 3 (Destexhe et al., 1994). Details about the connectivity of A1 and Par2 are in Tables 4 and 5, respectively. We instantiated 10 networks, each of which was randomly and independently generated according to the same rule given in Tables 4 and 5 .
Synaptic connections between A1 and Par2. Two cortical areas were connected with bottom-up and top-down signal pathways (see Fig. $1 B$ ) adopted from hierarchical structures proposed by Felleman and Van Essen (1991) (see also Markov and Kennedy, 2013). In our model, superficial RS cells of Par2 target both superficial RS and FS cells of A1; because the main target of top-down signals is FS interneurons (Mitchell et al., 2007), stronger inputs were projected to FS cells. Deep layer pyramids of Par2 project to L5 pyramids and L5 SI cells of A1. Roopun et al. (2010) found that gamma and beta rhythms were prominent in superficial and deep layers, respectively, and that there was strong coherence in local field potentials (LFPs) in the gamma- and beta-frequency bands. These findings support the use in the model of the deep-deep and superficial-superficial top-down connections. For the bottom-up pathway, we included projection from L2/3 RS cells to L4 E and FS cells of Par2. All of these intercortical connections are excitatory and identical to AMPA connections within an individual area except for the slow kinetics (Table 3). The details of intercortical connections are in Table 6.

Simulation of the presence of kainate. Kainate receptor activation is capable of generating rhythmic activity in both A1 and Par2. Ainsworth et al. (2011) showed that kainate at a $400 \mathrm{~nm}$ concentration induces prominent gamma rhythms in superficial layers, but weak activity in other layers of A1. In contrast, in Par2, kainate generates prominent beta rhythmic activity in deep layers as well as gamma rhythmic activity in superficial layers of Par2. Earlier computational works (Kramer et al., 2008; Ainsworth et al., 2011) modeled kainate-induced gamma rhythms by driving pyramidal cells with applied currents and/or spike trains of EPSCs. Here, we used both types of inputs to pyramidal cells to simulate the presence of kainate drive. Inhibitory cells also received tonic applied currents. The details of external inputs simulating the presence of kainate are given in Table 2.

Simulation of the presence of cholinergic neuromodulation. Cholinergic modulation is capable of regulating the excitability of non-FS interneurons, modeled with SI cells, via nicotinic receptors and synaptic transmission of inhibitory connections (Xiang et al., 1998; Gulledge et al., 2007; Levy et al., 2008). In sensory cortex, Xiang et al. (1998) found that acetylcholine, a cholinergic neuromodulator, depolarizes L5 LTS cells, but hyperpolarizes L5 FS cells. L5 deep LTS cells are important for the generation of cholinergically induced deep layer beta rhythms (Roopun et al., 2010). Therefore, we considered four effects of cholinergic modulation in A1. First, both superficial and deep layer SI cells were depolarized (Arroyo et al., 2012). Second, the amplitude of inhibition by FS cells was reduced by $50 \%$ in granular layers to simulate the effects of muscarine application (Kruglikov and Rudy, 2008). Third, deep layer FS cells were hyperpolarized. Fourth, the M-current of individual cells was reduced by $50 \%$. In contrast to A1, cholinergic modulation failed to generate rhythmic activity in Par2 (Roopun et al., 2010). Therefore, we assumed limited cholinergic modulatory effects in Par2: we implemented the reduction of M-currents in L2/3 RS and all SI cells, as shown Table 2, and reduced inhibition of L4 FS cells by $50 \%$.

Estimates of LFPs and spike-field coherence. We simulated LFPs by summing up synaptic currents projecting onto pyramidal cells from all neurons within the same cortical area (Mazzoni et al., 2008). LFPs were calculated in each layer. That is, superficial, granular, and deep layerLFPs were calculated independently with total synaptic inputs to pyramidal cells in each layer. We report the mean value of 10 power spectra, each of which was calculated from an independently instantiated network using a different random seed. We also calculated the spectral power of a population spiking activity of some types of cells. Specifically, we estimated the output field by constructing the histograms of action potentials of 20 cells with $0.01 \mathrm{~ms}$ bins. This population output field was also used for calculating spike-field coherence. All spectral analyses including spike-field coherence were calculated with Chronux, the MATLAB toolbox (Mitra and Bokil, 2007).

$G C$. To determine whether our model is capable of reproducing the causal relationship between A1 and Par2, we calculated the GC between LFPs of A1 and Par2 via the GCCA tool box running on MATLAB program environment (Seth, 2010). Because gamma and beta rhythms are prominent in the superficial and deep layers of both regions, respectively, we calculated the GC between the superficial layers of the two regions and the deep layers of the regions (Roopun et al., 2010; Xiao-jing Wang, 
Table 1. Static state variables and forward and backward rate functions

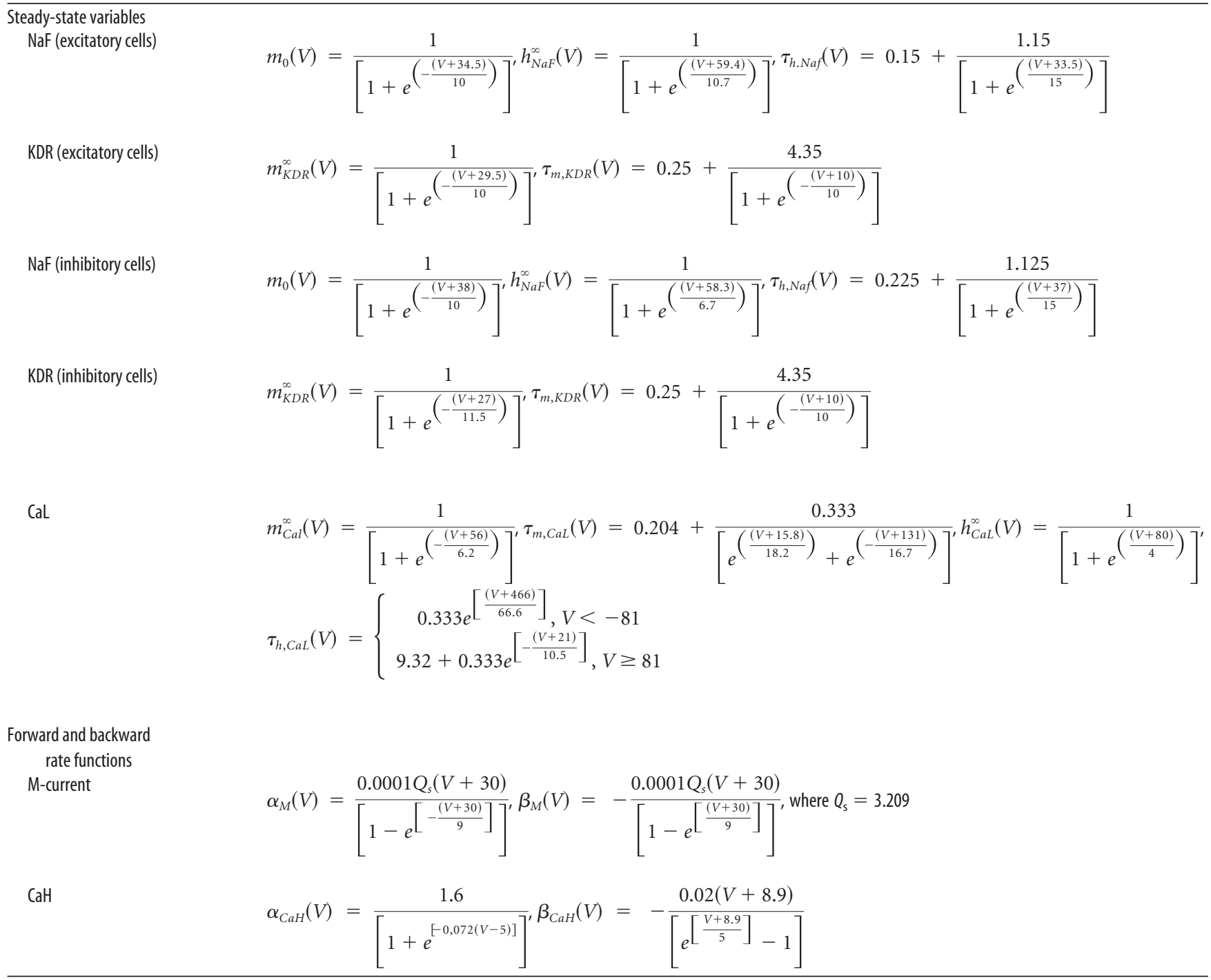

2010). Before calculating GC, LFPs were downsampled to $200 \mathrm{~Hz}$. We also merged 10 traces of LFPs obtained from 10 independent simulations into a long-time series to compute GC.

\section{Results}

We describe below our simulation results regarding inter-areal interactions between $\mathrm{A} 1$ and Par2 and the functional role of cholinergic modulation on these interactions. To reduce confusion, distinct terminology is used for inter-areal and inter-laminar interactions throughout this section: top-down (bottom-up) signals refer to inter-areal interactions from Par2 (A1) to A1 (Par2), whereas ascending (descending) signals refer to inter-laminar interactions from lower (upper) to upper (lower) laminar layers.

\section{Kainate-induced rhythmic activity}

We started by creating isolated models for A1 and Par2 to replicate rhythmic activity reported in the two areas (Roopun et al., 2006, 2010). We then connected A1 and Par2 with the top-down and bottom-up pathways (see Materials and Methods) to understand neural mechanisms underlying causal interaction between the two areas and the implications of the results for in vivo processing.
Isolated Model A1 and Par2 are capable of reproducing kainate-induced rhythmic activity

Figure 1, $C$ and $D$, display the power spectra of LFPs averaged from 10 independent stimulations. The simulated LFPs of our model show rhythmic activity consistent with that reported in experimental studies (Roopun et al., 2006, 2010; Ainsworth et al., 2011). In the superficial layers of A1 and Par2, prominent gamma rhythms are generated with a small frequency difference (Fig. $1 C$ ); this frequency difference is consistent with physiological observations that Par2 rhythms (Roopun et al., 2010) were faster than A1 rhythms (Ainsworth et al., 2011). A broad peak in the gamma-frequency band appears in the power spectrum in deep layer LFPs in A1, whereas a prominent peak of Par2 deep layer LFP power is in a beta frequency $(\sim 20 \mathrm{~Hz})$, as can be seen in Figure $1 D$.

\section{Kainate-induced superficial gamma rhythms generate} unidirectional communication from Par2 to A1

To elucidate potential mechanisms underlying unidirectional communication from Par2 to A1, we connect the model A1 and model Par2 with top-down and bottom-up connections (see Fig. $1 B$ and Materials and Methods). Superficial RS and FS cells of A1 receive excitation from Par2 at a frequency slightly faster than 40 
Table 2. Maximal conductance of intrinsic currents and external inputs

\begin{tabular}{|c|c|c|c|c|c|c|c|}
\hline & $\mathrm{g}_{L}\left(\mu \mathrm{S} / \mathrm{cm}^{2}\right)$ & $g_{M}$ & $g_{\mathrm{CaH}}$ & $g_{\mathrm{Cal}}$ & $g_{h}$ & $l_{a p p}\left(n A / \mathrm{cm}^{2}\right)$ & $g_{E x t}$ \\
\hline \multicolumn{8}{|l|}{ A1 } \\
\hline L2/3 RS & 0.1 & $0.3 / 0.6$ & 0 & 0 & 0 & $-2(0.5)$ & 0.5 \\
\hline $\mathrm{L} 2 / 3 \mathrm{FS}$ & 0.1 & 0 & 0 & 0 & 0 & $0(0.5)$ & 0 \\
\hline $\mathrm{L} 4 \mathrm{E}$ & 0.1 & $0.9 / 1.8$ & 0 & 0 & 0 & $-10(0)$ & 0.1 \\
\hline L4FS & 0.1 & 0 & 0 & 0 & 0 & $-5(0.5)$ & 0.03 \\
\hline L5 IB (axon) & 0.1 & $0.3 / 0.6$ & 0 & 0 & 0 & $0.8(0.1)$ & 0 \\
\hline L5 RS (axon) & 0.1 & $0.3 / 0.6$ & 0 & 0 & 0 & $0.8(0.1)$ & 0 \\
\hline L5 RS (soma) & 0.1 & 0 & 0 & 0 & 0 & $-1.4(0.1)$ & 0 \\
\hline L5 RS (dendrite) & 0.1 & $0.6 / 1.2$ & 2 & 0 & 0 & $-5(0.3)$ & 0.1 \\
\hline L5FS & 0.1 & 0 & 0 & 0 & 0 & $4(0.5) /-1.3(0.5)$ & 0 \\
\hline L5SI & 0.1 & $3 / 6$ & 0 & 0.3 & 0 & $-4(0.8) / 2.6(0 / 8)$ & 0 \\
\hline \multicolumn{8}{|l|}{ Par2 } \\
\hline L4FS & 0.2 & 0 & 0 & 0 & 0 & $-4(0.5)$ & 0.1 \\
\hline L5 IB (axon) & 0.1 & 8 & 0 & 0 & 0 & $-5(0.1)$ & 0 \\
\hline L5 IB (soma) & 0.1 & 0 & 0 & 0 & 0 & $-5(0.1)$ & 0 \\
\hline L5 IB (dendrite) & 0.1 & 2 & 4 & 0 & 0.1 & $-5(0.3)$ & 0 \\
\hline L5 RS (axon) & 0.1 & 8 & 0 & 0 & 0 & $-2(0.1)$ & 0 \\
\hline L5 RS (soma) & 0.1 & 0 & 0 & 0 & 0 & $-3(0.1)$ & 0 \\
\hline L5 RS (dendrite) & 0.1 & 3 & 2 & 0 & 0.1 & $-1(0.3)$ & 0 \\
\hline L5FS & 0.1 & 0 & 0 & 0 & 0 & $0(0.5)$ & 0 \\
\hline $\mathrm{L} 5 \mathrm{SI}$ & 0.1 & $3 / 6$ & 0 & 0.5 & 0 & $-3(0.8) / 3(0.8)$ & 0 \\
\hline
\end{tabular}

For each compartment, noisy tonic drive $\left(I_{\text {app }}\right)$ was introduced. Mean values are displayed; the numbers inside parentheses are $S D$ s. If a pair of numbers is given, the first and second shows parameters with and without cholinergic modulation, respectively.

Table 3. Rise time and decay time of synapses used in our model

\begin{tabular}{llc}
\hline & Rise (msec) & Decay (msec) \\
\hline Excitatory synapses & 0.25 & 1 \\
Intercortical synapses & 2 & 4 \\
NMDA synapses & 5.0 & 100 \\
Inhibitory synapses from FS cells & 0.5 & 8 \\
Inhibitory synapses from SI cells & 0.5 & 20 \\
Excitatory synapses from L5 to L2/3 SI cells & 2.5 & 50 \\
\hline
\end{tabular}

All intercortical synapses are excitatory, but they have slower kinetics than intracortical ones. Non-fast-spiking interneurons elicited slowly decaying inhibition (Otsuka and Kawaguchi, 2009; Thomson et al., 1996), and inhibition of L5 Martinotti cells has slower kinetics than that of L5 FS cells (Silberberg and Markram, 2007). Therefore, we set SI to produce slowly decaying inhibition. Specifically, we adopted decaying time from models of low-thresholdspiking interneurons in earlier computational works (Kramer et al., 2008; Traub et al., 2005).

$\mathrm{Hz}$, whereas deep layer pyramidal cells (IB and RS) and SI interneurons in Al receive beta rhythmic excitation. In the kainate model, only superficial layer cells respond to top-down signals: A1 superficial layer rhythms become faster and resonant to those of Par2 (Fig. 1E). Despite top-down beta rhythms introduced to L5 cells of A1, deep layer cells of A1 still generate rhythmic activity mainly in the gamma-frequency band, incoherent with top-down beta signals (Fig. $1 F$ ). We note that L5 SI cells of A1, believed to be critical in the generation of A1 deep-layer beta rhythms, fire more sparsely than those of Par2 (Fig. 2E,F). The activity of this cell type is sensitive to the presence of cholinergic modulation (see below and Figure $6 A$ ) and this can account for the lack of coherence in the beta-frequency band shown in Figure $1 F$.

Figure 2 shows layer-specific neural responses of both A1 and Par2 with inter-areal connections. Consistent with physiological studies, modeled FS cells in superficial and deep layers fire in the gamma-frequency band, generating gamma rhythms in LFPs. In our model, L4 E cells fire sparsely (Fig. 2C), corresponding to moderate granular layer activity induced by kainate at $400 \mathrm{nM}$ (Ainsworth et al., 2011). When FS cells in both superficial and deep layers are actively involved in generation of gamma rhythms, they project strong inhibition to SI cells, suppressing SI cell activity in both layers. However, we note that L2/3 SI cells of A1 fire strongly during certain periods of time. This enhanced activity is induced by the strong ascending excitatory projection from L5 pyramidal cells. Once L2/3 SI cells of A1 start firing in response to ascending excitation, FS cell activity is suppressed and thus SI cells can be released from strong inhibition, allowing SI cells to fire even more strongly. This active firing of SI cells can be sustained for a short period time because SI cells receive slowly decaying excitation from L5 pyramidal cells (see Materials and Methods). During this active firing, M-currents accumulate inside SI cells, making them unresponsive until M-currents decay. Due to a combination of dynamics of $\mathrm{M}$-current and strong inhibition from FS cells, SI cells cannot fire frequently. This may account for the slower alternation of active and inactive firing of SI cells (Fig. 2A).

We calculated the GC in our model data to determine whether top-down interactions from Par2 to A1 are capable of reproducing the unidirectional causal relationship between the two areas reported in Roopun et al. (2010). We used 10 independent simulations to estimate the GC (see Materials and Methods). As can be seen in Figure 2G, the GC estimated between superficial layer LFPs shows a (mainly) unidirectional communication from Par2 to A1 in the gamma-frequency band, suggesting that the topdown pathway between superficial layers can mediate the essentially unidirectional communication observed experimentally (Roopun et al., 2010). We also note weak top-down signals in the beta-frequency band and the GC between deep layers mirrors that between superficial layers (Fig. 2H). 
Table 4. Connectivity map in A1

\begin{tabular}{|c|c|c|c|c|c|c|c|c|c|}
\hline \multirow[b]{2}{*}{ No. of presynaptic cells } & \multicolumn{3}{|l|}{$L 2 / 3$} & \multicolumn{2}{|l|}{ L4 } & \multicolumn{4}{|l|}{$\mathrm{L} 5$} \\
\hline & RS & FS & SI & $E$ & FS & IB & RS & FS & $\mathrm{SI}$ \\
\hline \multicolumn{10}{|l|}{ L2/3 } \\
\hline RS & $10(0.02)$ & $20(0.3)$ & $10(0.03)$ & 0 & 0 & $20(0.05)$ & $20(0.05)$ & $20(0.4)$ & 0 \\
\hline FS & $10(1.2)$ & $10(0.2)$ & $10(0.6)$ & $8(0.03)$ & 0 & 0 & 0 & 0 & 0 \\
\hline SI & $10(0.02)$ & $10(1.0)$ & $2(0.2)$ & 0 & 0 & $10(0.01)$ & $10(0.01)$ & 0 & 0 \\
\hline \multicolumn{10}{|l|}{ L4 } \\
\hline $\mathrm{E}$ & $10(0.3)$ & 0 & 0 & $10(0.03)$ & $20(0.25)$ & $10(0.01)$ & $10(0.01)$ & 0 & 0 \\
\hline FS & $10(0.1)$ & 0 & 0 & $20(0.3 / 0.6)$ & $20(0.3)$ & 0 & 0 & 0 & 0 \\
\hline \multicolumn{10}{|l|}{ L5 } \\
\hline IB & 0 & $2(0.1)$ & $2(0.25)$ & 0 & 0 & $5(0.02)$ & $5(0.01)$ & $10(0.3)$ & $10(0.2)$ \\
\hline RS & 0 & $2(0.1)$ & $2(0.25)$ & 0 & 0 & $5(0.01)$ & $5(0.01)$ & $10(0.3)$ & $10(0.2)$ \\
\hline FS & 0 & 0 & 0 & 0 & 0 & $20(0.4)$ & $20(0.4)$ & $20(0.8)$ & $10(0.8)$ \\
\hline SI & 0 & $10(0.02)$ & 0 & 0 & $10(0.6)$ & $20(0.5)$ & $20(0.5)$ & $10(0.03)$ & $20(0.4)$ \\
\hline
\end{tabular}

In our model, each postsynaptic cell received synaptic inputs from various types of cells. The rows show the type of postsynaptic cells and columns represent presynaptic cells. We list how many presynaptic cells of a particular type were connected to a postsynaptic cell. For example, L2/3 FS cells received excitation from $2 \mathrm{~L} 5 \mathrm{IB}$ cells. The numbers inside parentheses are maximal conductance of corresponding synapses. If a pair of numbers is given, the first and second shows parameters with and without cholinergic modulation, respectively. In addition, L2/3 FS and SI cells received excitation from 10 L2/3 RS cells via NMDA synapses; the maximal conductance value was $0.01 \mu \mathrm{S} / \mathrm{cm}^{2}$. Because Roopun et al. (2010) suggested that only L5SI cells produced inhibition oscillating in the beta-frequency band and that all L5 cells received beta rhythmic inhibition, all L 5 cells of our model received inhibition from L $5 \mathrm{SI}$ cells. Also, we made inhibitory connections among L2/3 SI cells sparse (Gibson et al., 1999).

Table 5. Connectivity map in Par2

\begin{tabular}{|c|c|c|c|c|c|c|c|c|c|}
\hline \multirow[b]{2}{*}{ No. of presynaptic cells } & \multicolumn{3}{|l|}{$L 2 / 3$} & \multicolumn{2}{|l|}{ L4 } & \multicolumn{4}{|l|}{$\mathrm{L} 5$} \\
\hline & RS & FS & SI & $E$ & FS & IB & RS & FS & SI \\
\hline \multicolumn{10}{|l|}{$\mathrm{L} 2 / 3$} \\
\hline RS & $10(0.3)$ & $20(0.3)$ & $10(0.02)$ & 0 & 0 & $20(0.01)$ & $20(0.01)$ & $20(0.01)$ & 0 \\
\hline FS & $10(1.4)$ & $10(0.5)$ & $10(0.4)$ & $8(0.2)$ & 0 & 0 & 0 & 0 & 0 \\
\hline SI & $10(0.05)$ & $10(0.2)$ & 0 & 0 & 0 & $10(0.1)$ & $10(0.1)$ & 0 & 0 \\
\hline \multicolumn{10}{|l|}{ L4 } \\
\hline$E$ & $10(0.05)$ & 0 & 0 & $10(0.02)$ & $20(0.1)$ & $10(0.01)$ & $10(0.01)$ & $20(0.02)$ & 0 \\
\hline FS & $10(0.05)$ & 0 & 0 & $20(0.5 / 1.0)$ & $20(0.2)$ & 0 & 0 & 0 & 0 \\
\hline \multicolumn{10}{|l|}{$\mathrm{L} 5$} \\
\hline IB & 0 & $2(0.01)$ & $2(0.1)$ & 0 & 0 & $5(0.25)$ & $5(0.02)$ & $10(0.2)$ & $10(0.2)$ \\
\hline $\mathrm{RS}$ & 0 & $2(0.01)$ & $2(0.1)$ & 0 & 0 & 0 & $5(0.02)$ & $10(0.2)$ & $10(0.2)$ \\
\hline FS & 0 & 0 & 0 & 0 & 0 & $20(0.01)$ & $20(0.1)$ & $20(0.6)$ & $10(0.05)$ \\
\hline SI & 0 & $10(0.5)$ & $10(0.1)$ & 0 & $10(0.34)$ & 0 & $20(0.4)$ & $10(0.4)$ & $20(0.6)$ \\
\hline
\end{tabular}

The structure of Par2 is almost identical to that of A1 with two major differences. First, axons of $\mathrm{L} 5 \mathrm{IB}$ cells were connected via axonal-axonal gap junctions (Kramer et al., 2008 ). In our model, $7 \mathrm{IB}$ cells were randomly connected together and the strength of gap junction is $0.04 \mu \mathrm{S} / \mathrm{cm}^{2}$. Second, we removed inhibitory connections from L5 SI to L5 IB cell (Kramer et al., 2008). As in A1, L2/3 FS and SI cells received excitation from 10 L2/3 RS cells via NMDA synapses; the maximal conductance values were 0.01 and $0.05 \mu \mathrm{S} / \mathrm{cm}^{2}$, respectively.

Table 6. Inter-areal connections

\begin{tabular}{llc}
\hline & Maximal conductance & No. of presynaptic cells \\
\hline Top-down (from Par2 to A1) & & \\
L2/3 RS $\rightarrow$ L2/3 RS & 0.1 & 20 \\
L2/3 RS $\rightarrow$ L2/3 FS & 0.25 & 20 \\
L5 IB $\rightarrow$ L5 IB & 0.12 & 2 \\
L5 IB $\rightarrow$ L5 RS & 0.12 & 2 \\
L5 IB $\rightarrow$ L5 SI & 0.05 & 10 \\
L5 RS $\rightarrow$ L5 IB & 0.1 & 2 \\
L5 RS $\rightarrow$ L5 RS & 0.1 & 2 \\
L5 RS $\rightarrow$ L5LTS & 0.05 & 10 \\
Bottom-up (from A1 to Par2) & & \\
L2/3 RS $\rightarrow$ L4 E & 0.6 & 10 \\
L2/3 RS $\rightarrow$ L4 FS & 0.04 & 10 \\
\hline
\end{tabular}

We list inter-areal connections with maximal conductance and the number of presynaptic cells connected to a particular postsynaptic cell. Left and right sides of an arrow represent presynaptic and postsynaptic cells, respectively.

\section{Top-down signals to L2/3 FS cells regulate L2/3 RS cell activity} in A1 indirectly

The top-down pathways between superficial layers of Par2 and A1 target both RS cells and FS cells. To distinguish the functional roles of these two pathways, we further investigated the effects of top-down signals to L2/3 RS and FS cells of A1 on the GC. We varied the maximal conductance of top-down signals and calculated the GC between the superficial layers of A1 and Par2. Our simulation results below suggest that both top-down pathways play roles in establishing the causal relationship, but in different manners.

As can be seen in Figure 3A, the GC is strongly dependent on synaptic connections to RS cells of A1. Without top-down signals to $\mathrm{L} 2 / 3 \mathrm{RS}$ cells, the GC is negligible and it grows as top-down signals to L2/3 RS cells become stronger. Figure $3 B$ shows that the GC is also correlated to top-down signals to FS cells, but in a more complicated way. If top-down signals to FS cells are reduced from our default value $\left(0.25 \mu \mathrm{S} / \mathrm{cm}^{2}\right)$, then the GC values are reduced. However, when we further increase top-down signals to FS cells, the GC becomes smaller instead of bigger, indicating that the GC and topdown signals to FS cells are not always positively correlated with each other.

This behavior can be explained by the role of FS cells in generation of gamma rhythms: FS cells can synchronize RS cell activity by preventing RS cells from spiking randomly between cycles (Börgers and Kopell, 2005, 2008). Although FS cells in A1 receive strong top-down signals, they cannot fire at every cycle of top-down signals because they also receive local inhibition from other FS cells and from SI cells within A1. When L2/3 FS cells of A1 skip cycles, L2/3 RS cell activity of A1 becomes asynchronous and thus gamma power is also reduced. Enhanced top-down signals to FS cells help them to fire in the gamma-frequency band, accounting for the positive correlation between the GC and topdown signals to FS cells when the latter is moderate in size. In 
A

$\mathrm{L} 2 / 3$

L4

L5

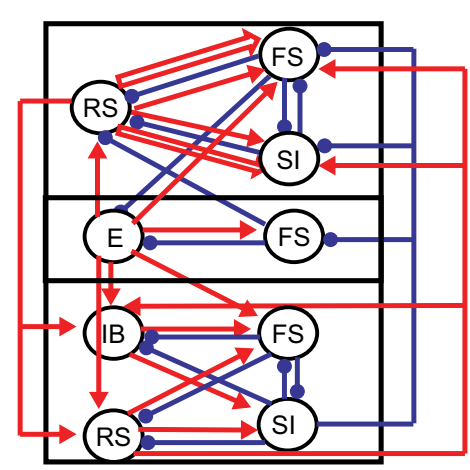

B

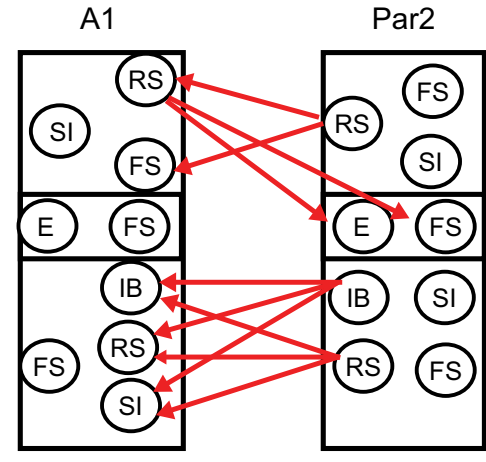

$\Rightarrow$ NMDA $\rightarrow$ AMPA $\longrightarrow$ GABA

C

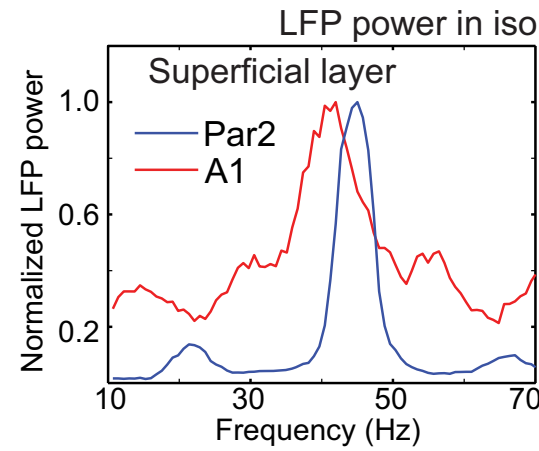

D

$\mathbf{E}$

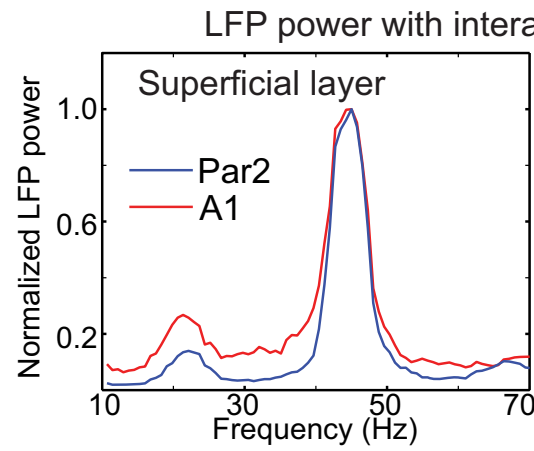

LFP power with interaction between A1 and Par2

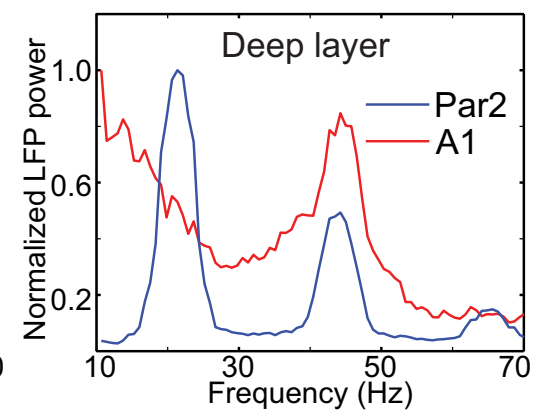

Figure 1. The structure of the model and kainate-induced LFPs. $A$, Structure of a single column of A1. Each circle is a population of 20 cells. Open and solid arrows represent NMDA and AMPA synapses, respectively. Blue circles are GABA synapses. Par2 was built using the same structure, but we made two changes in the deep layer of Par2: inhibition from L5 SI to L5 IB cells was removed and L5 IB cells were connected via axonal-axonal gap junctions (see text and Kramer et al., 2008). B, Full model with intercortical connections. $L 2 / 3$ and $L 5$ of Par2 sent top-down signals into $L 2 / 3$ and $L 5$ of $A 1$, respectively. In contrast, $L 2 / 3 \mathrm{~A} 1$ sent bottom-up signals into $\mathrm{L} 4$ of Par2. We did not display recurrent connections inside the neuron population: all neurons receive recurrent inputs from other others that belong to the same population (see Materials and Methods). C, D, Power spectral density of LFPs in superficial and deep layers of A1 and Par2 without interactions between the two areas. The red and blue represent LFP power from A1 and Par2, respectively. Similarly, spectral power of $\mathrm{A} 1$ and Par2 with interaction between them is shown in $\boldsymbol{E}$ and $\boldsymbol{F}$.

contrast, if top-down signals to FS cells are too strong, FS cells can fire without local excitation from RS cells, reducing L2/3 RS cell activity. As can be seen in Figure 3C, L2/3 RS cell activity is further reduced when the maximal conductance of top-down signals to FS cells is increased to $0.3 \mu \mathrm{S} / \mathrm{cm}^{2}$.

Top-down gamma rhythms can prevent L2/3 RS cells from responding to excitatory projection from $\mathrm{L} 4 \mathrm{E}$ cells

Our model simulation results above suggest that top-down signals can induce resonating gamma rhythmic activity, but what are the functional roles of top-down gamma rhythms? Earlier computational work proposed that gamma rhythms (especially PING-like rhythms) can filter out undesirable signals (Börgers and Kopell, 2008). Indeed, as can be seen in Figure 2, $A$ and $C$, although $\mathrm{L} 4 \mathrm{E}$ cells fire frequently from 500 to $700 \mathrm{~ms}, \mathrm{~L} 2 / 3$ RS cells are quiescent during that period of time. These facts lead us to the hypothesis that topdown gamma rhythms can effectively prevent L2/3 RS cells from responding to ascending signals, suppressing bottom-up signal processing associated with auditory stimuli. To address this hypothesis, we simulated strong thalamic inputs to L4 E cells of A1 and examined whether topdown gamma rhythms can prevent L $2 / 3$ RS cells from responding to ascending excitation from L4 E cells induced by thalamic inputs. Specifically, we strengthened asynchronous trains of EPSC introduced to L4 E cells by $150 \%$ and also reduced the applied current simulating in vitro stimulation to $\mathrm{L} 4$ cells by $80 \%$. These two changes ensured that L4 E cells of A1 were stimulated by temporally varying spike trains mimicking in vivo thalamic inputs to L4 cells.

As expected, L2/3 RS cells fired very sparsely (Fig. 4A), even with continuous L4 E cell activity (Fig. 4B), supporting our hypothesis that top-down gamma rhythms can suppress bottom-up communication associated with auditorystimulus-induced thalamic inputs (Fig. 4C).

Below, we focus on replicating the effects of cholinergic modulation on temporal interactions in vitro recording. In doing so, we keep using the tonic input to L4 cells unless stated otherwise.

\section{Functional role of} cholinergic modulation

Cholinergic modulatory effects on rhythmic activity were observed only in A1 (Roopun et al., 2010); cholinergic modulation induced deep layer beta rhythms in A1 and triggered bottom-up signals in a gamma frequency from A1 to Par2. To investigate the effects of cholinergic modulation on temporal interactions between A1 and Par2, we first added cholinergic modulation to the modeled A1 isolated from Par2 and then focused on the effects of cholinergic modulation on temporal interaction between the two areas.

\section{Cholinergic modulation can change neural responses in all layers of $\mathrm{A} 1$}

Figure 5 compares neural responses of three layers of isolated A1 with and without cholinergic modulation, indicating that the effects of cholinergic modulation are prominent in all layers of 
model A1. Cholinergic modulation depolarizes L5 SI cells (Xiang et al., 1998), significantly ( $t$ test $p<0.01$ ) increasing the firing rate of those cells in our model (Fig. $6 A)$. Enhanced SI cell activity reduces L5 pyramidal cell activity (Fig. $5 E, F$ ) and forces them to fire synchronously in the beta-frequency band; that is, deep layer beta rhythms are generated by feedback loops between L5 pyramids and L5 SI cells and slowly decaying inhibition of SI cells keep them in the beta-frequency band (Roopun et al., 2010). In the granular layer, L4 E cell activity was significantly $(t$ test, $p<0.01)$ increased by the application of cholinergic modulation (Fig. $6 B$ ). Without cholinergic modulation, some L4 FS cells fired asynchronously, generating strong inhibition impinging on L4 E cells and suppressing L4 E cell activity (Fig. 5C). In contrast, the application of cholinergic neuromodulation reduced inhibition impinging onto L4 E cells in two ways. First, cholinergic modulation reduced inhibition of L4 FS cells directly, as suggested in Kruglikov et al. (2008). Second, the ascending inhibition from L5 SI cells to L4 FS cells suppressed L4 FS cell activity indirectly, reducing inhibition. Due to reduced inhibition, L4 E cells are able to fire and excite L4 FS cells, generating PING-like rhythms (Whittington et al., 2000; Börgers and Kopell, 2005). The details of inter-laminar interactioninduced disinhibition were addressed in our earlier work (Lee et al., 2013).

Notably, cholinergically enhanced L4 E cell activity generates a stronger excitatory projection to $\mathrm{L} 2 / 3$ cells, thereby inducing stronger L2/3 cell activity. As can be seen in Figure 5B, RS cells fire more strongly and synchronously in the presence of cholinergic modulation. It is also noteworthy that L2/3 SI cell activity is significantly ( $t$ test, $p<0.01$ ) increased (Fig. $6 C)$. Cholinergic modulation can enhance superficial layer RS cell activity by increasing the L4 E cell response, suggesting that cholinergic modulation may induce $\mathrm{A} 1$ to generate stronger outgoing corticocortical signals. To determine whether these cholinergically enhanced outputs of A1 can account for bottom-up inputs from A1 to Par2 in the gamma-frequency band, we repeated the same simulation with the entire network in which A1 and Par2 interacted with each other (see below).

\section{Cholinergic modulation can help A1 send bottom-up signals to Par2}

Figure 7 shows neural responses of A1 and Par 2 with inter-areal connections in the presence of both kainate and cholinergic modulation. The GC values shown in Figure $7 G$ confirm that cholinergic modulation can generate bottom-up signals in the gamma-
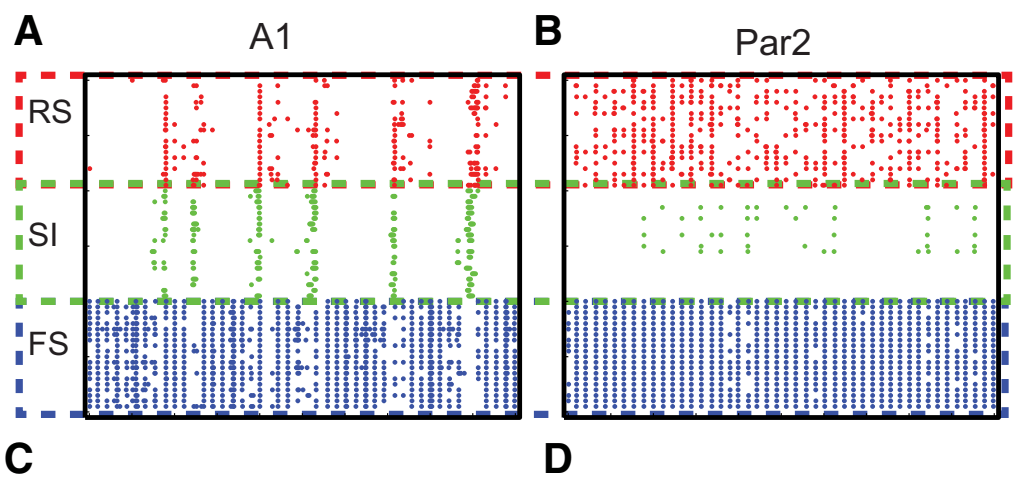

D

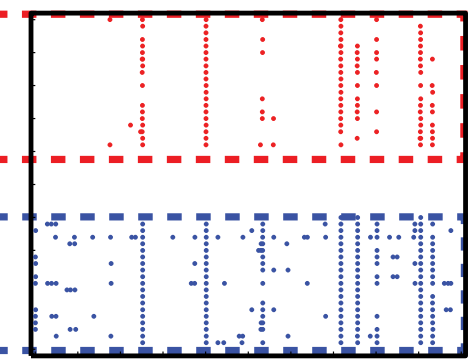

$\mathbf{F}$
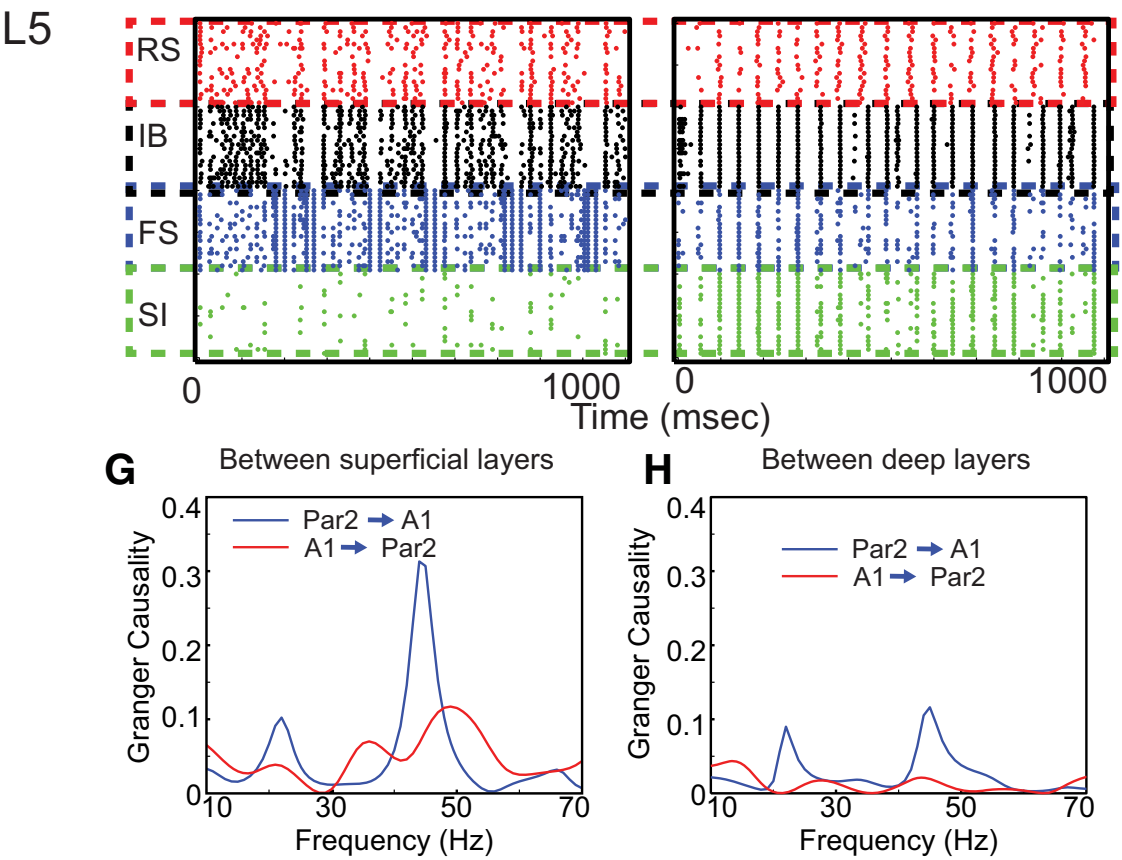

H Between deep layers

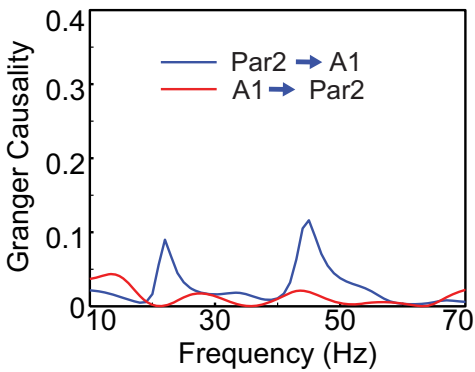

Figure 2. Layer-specific cell activity in the presence of kainate and causal interaction between the two areas. All panels show neural responses with synaptic connections between $A 1$ and Par2. $A, B$, Superficial neural responses of $A 1$ and Par2. $C, D$ and $E, F$, $L 4$ and $L 5$ responses, respectively. Each dot represents an action potential. $x$-axis shows simulation time and $y$-axis displays the cell number. G, GC between superficial layer LFPs. $\boldsymbol{H}, \mathrm{GC}$ between deep layer LFPs.

frequency band. With cholinergically induced beta rhythms in deep layers of A1, deep layer cells of both A1 and Par2 generate beta rhythms. This allows Par2 deep layer cells to entrain A1 deep layer cells via the top-down pathway between deep layers, enhancing the unidirectional signals in the beta-frequency band (Figs. $7 \mathrm{H}, 2 \mathrm{H}$ ), suggesting that cholinergic modulation allows deep layer cells and superficial layer cells to respond to top-down signals: In the absence of cholinergic modulation, deep layer pyramidal cells of A1 fire in a gamma frequency and top-down beta rhythms cannot entrain those cells. In contrast, L5 pyramidal cell activity is suppressed due to enhanced L5 SI cell activity in the 
A

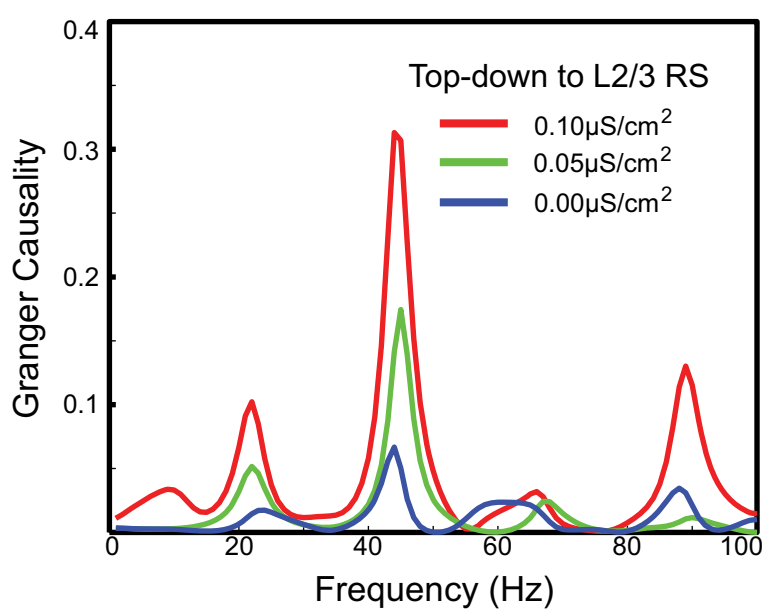

B

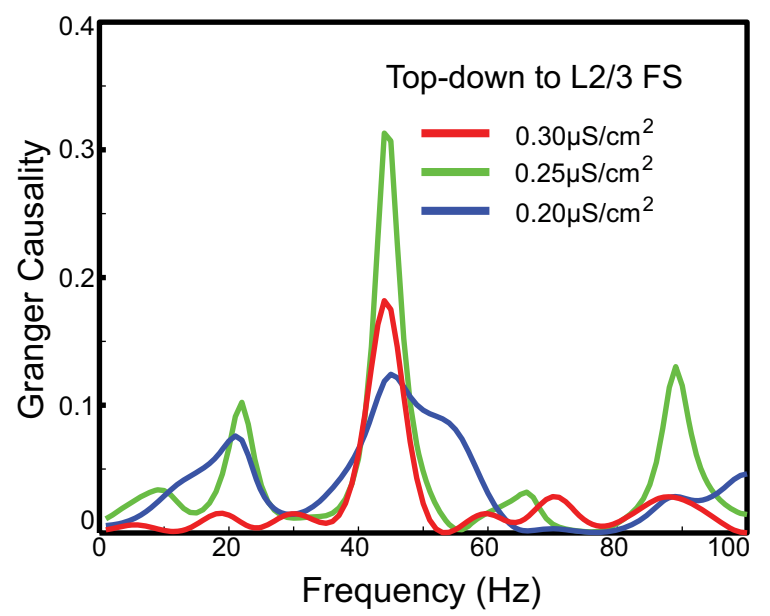

C

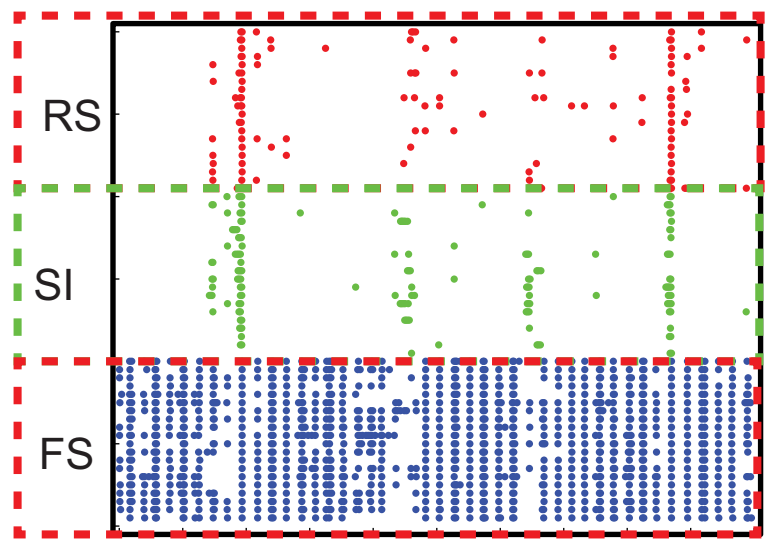

Figure 3. Causal relationship dependent on top-down connections. $A, \mathrm{GC}$ between superficial layer LFPs from Par2 to A1 as a function of strength of top-down signals to $L 2 / 3$ RS cells of A1. Numbers in the inset show the maximal conductances of top-down signals to $L 2 / 3 R S$ cells. $B, G C$ between superficial layer LFPs from Par2 to $A 1$ as a function of strength of top-down signals to L2/3 FS cells of A1; numbers in the inset show the maximal conductances of top-down signals to L2/3 RS cells. C, Superficial layer cell activity when the maximal conductance of top-down signals to FS cells is increased to $0.3 \mu \mathrm{S} / \mathrm{cm}^{2}$.

presence of cholinergic modulation (Fig. $5 E, F$ ), making L5 cells more sensitive to top-down beta rhythms. Importantly, we note that L5 SI cell activity is even further enhanced with top-down beta signals (Figs. 5F, 7E). Because L5 SI cells project ascending
A

A1

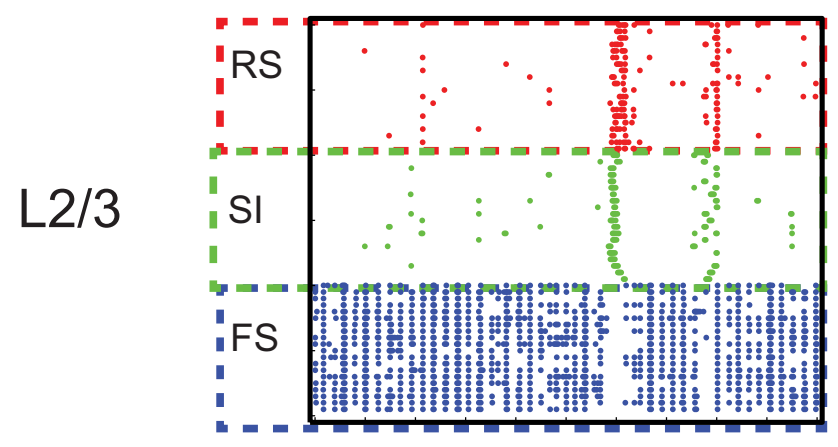

B
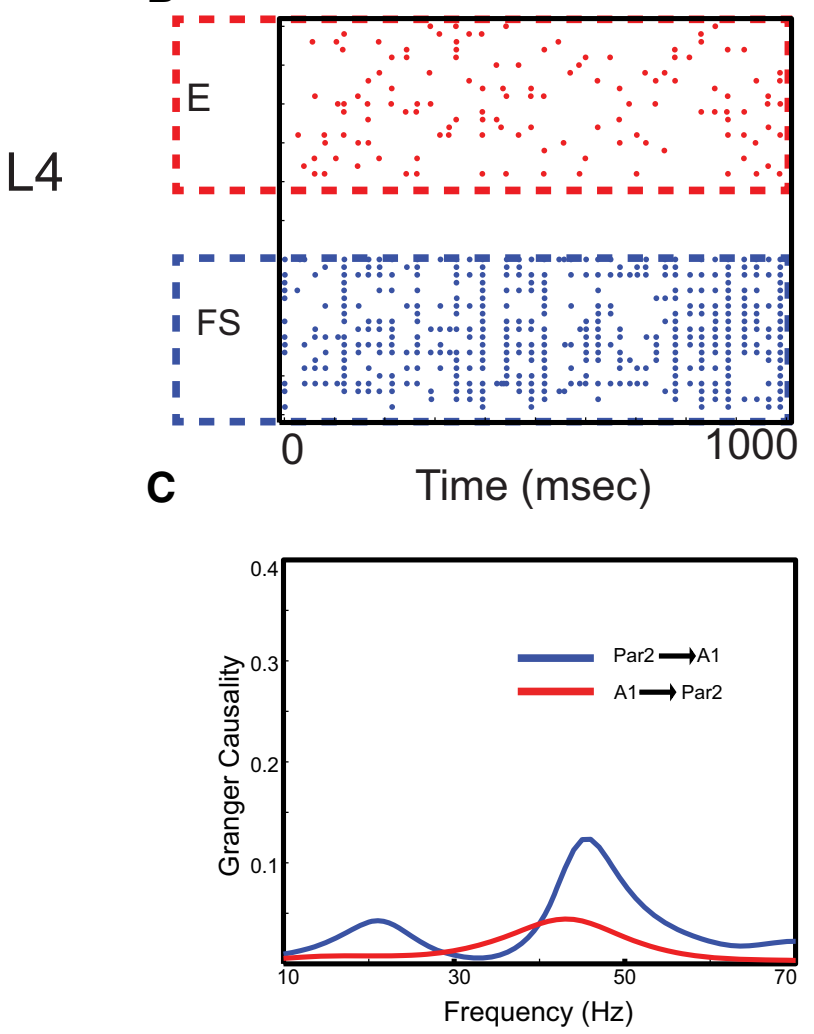

Figure 4. Blockade of bottom-up signals induced by top-down gamma rhythms. A, B, Superficial layer and granular cell activity. In this experiment, although L4E cells fire continuously, they cannot induce L2/3 RS cells to fire. C, GC between superficial layers, indicating that topdown communication is dominant even with a stronger $L 4 \mathrm{E}$ cell activity of A1.

inhibition to interneurons in superficial and granular layers, this enhanced deep layer beta rhythms reduce inhibition impinging onto pyramidal cells (RS and E) in L2/3 and L4, as discussed in our earlier computational study (Lee et al., 2013); that is, cholinergic modulation enables Par2 to induce inter-laminar interactions in A1, which is crucial for generating bottom-up gamma signals from A1 to Par2.

\section{L2/3 RS cell activity is phase locked to the L4 outputs in the} presence of cholinergic modulation

Cholinergically induced deep beta rhythms increase L4 E activity and thus ascending inter-laminar synaptic inputs from L4 to L2/3 cells in A1. Specifically, the enhanced ascending inhibition from L5 SI cells to L4 FS cells can increase L4 E cell activity by suppressing L4 FS cell activity (Fig. 5C,D; also see Lee et al., 2013 for detailed discussion). Therefore, L2/3 RS cells receive much stron- 
ger synaptic inputs from L4. The spikefield coherence between L2/3 RS cell activity and LFPs in L4, shown in Figure $8 A$, confirms that L2/3 RS cell activity is phase locked to synaptic inputs from L4. We note that the peak coherence appears around $50 \mathrm{~Hz}$, which is faster than the frequency of Al gamma rhythms (Fig. 1C) induced by kainate. This can be explained by the reduced inhibition from L4 FS to L4 E cells (see Materials and Methods). With reduced inhibition, L4 E cells can recover from inhibition generated by L4 FS cells more rapidly, so the period of synchronous activity becomes shorter. As a control experiment to verify that the spikefield coherence actually reflects the effect of ascending projection from L4 cells on L2/3 RS cells, we also displayed simulations without synaptic connections from L4 to L2/3 RS cells and calculated the spike-field coherence. As seen in Figure $8 B$, the peak at $\sim 50 \mathrm{~Hz}$ disappears, confirming that $\mathrm{L} 4$ cells induce active firing L2/3 RS cells at $\sim 50 \mathrm{~Hz}$.

\section{Deep-layer beta rhythms modulate superficial layer cell activity via inter- laminar interaction to $\mathrm{L} 2 / 3$ interneurons}

With deep layer beta rhythms induced by cholinergic drive, ascending synaptic inputs from L5 to L2/3 are modulated. First, the temporal frequency of ascending excitation from L5 pyramidal cells to L2/3 FS cells is reduced because L5 pyramidal cells fire now in the beta-frequency band instead of the gamma-frequency band. That is, FS cells become free from ascending excitation for a certain period of time, making FS cell activity phase locked to top-down signals more easily. The spike-field coherence between L2/3 FS cell activity of A1 and L2/3 LFPs of Par2 (Fig. 8C) confirms that FS cell activity is truly phase locked to the top-down gamma rhythms. This result is further supported by a control experiment in which top-down connections between superficial layers are removed. As seen in Figure $8 D$, the strong spike-field coherence at a frequency of $45 \mathrm{~Hz}$ disappears without top-down connections. It should be noted that a prominent peak exists at $\sim 50 \mathrm{~Hz}$, which is the frequency of bottom-up gamma rhythms (Fig. 8A) instead of that of top-down gamma rhythms. This result suggests that the coherence without top-down connections is induced by bottom-up signaling from A1 to Par2.

Second, L2/3 FS cells receive ascending inhibition in the betafrequency band from L5 SI cells due to increased activity of L5 SI cells. This means that L2/3 FS cell activity is indirectly suppressed by top-down beta rhythms. Third, L2/3 SI cells receive synchronous ascending excitation in the beta-frequency band from L5 pyramidal cells. Because this synaptic projection decays slowly, it can drive L2/3 SI cells to actively fire for a relatively prolonged period of time. After this active firing, M-currents accumulating in the L2/3 SI cell population make them unresponsive and skip some cycles of beta rhythms, generating slowly alternating active and inactive firing periods (Fig. 7A). Importantly, RS cells can fire in response to the ascending excitation from L4 E cells when SI cells suppress FS cell activity (Fig. 7A).

\section{Cholinergic modulation can enhance L2/3 RS cell activity in complementary ways}

The simulation results shown in Figures $4 A$ and $7 A$ suggest that $\mathrm{SI}$ and FS cells in $\mathrm{L} 2 / 3$ play distinctive roles in regulating L2/3 RS cell activity and thus bottom-up signaling from L2/3 RS cells of A1 to L4 E cells of Par2. FS cells reduce bottom-up signaling, but SI cells can lift the induced blockade. Because SI cells inhibit FS cells, SI cells can reduce inhibition impinging onto RS cells by suppressing FS cell activity. As discussed above, cholinergic modulation induces the ascending beta rhythmic input to L2/3 SI cells, allowing them to disinhibit RS cell activity. To further test whether SI cells can control RS cell activity, we measured the spectral power of spiking activity in L2/3 RS cells with reduced inhibition from SI to FS cells. In each simulation, we computed the spectral power between 45 and $60 \mathrm{~Hz}$ and display the mean values and the standard errors from 10 independent simulations in Figure $9 A$. As can be seen in the figure, the spectral powers of L2/3 RS cell outputs are positively correlated to the strength of inhibition, confirming that L2/3 SI cells can disinhibit RS cells in the presence of cholinergic modulation. We repeated the same experiments 
A

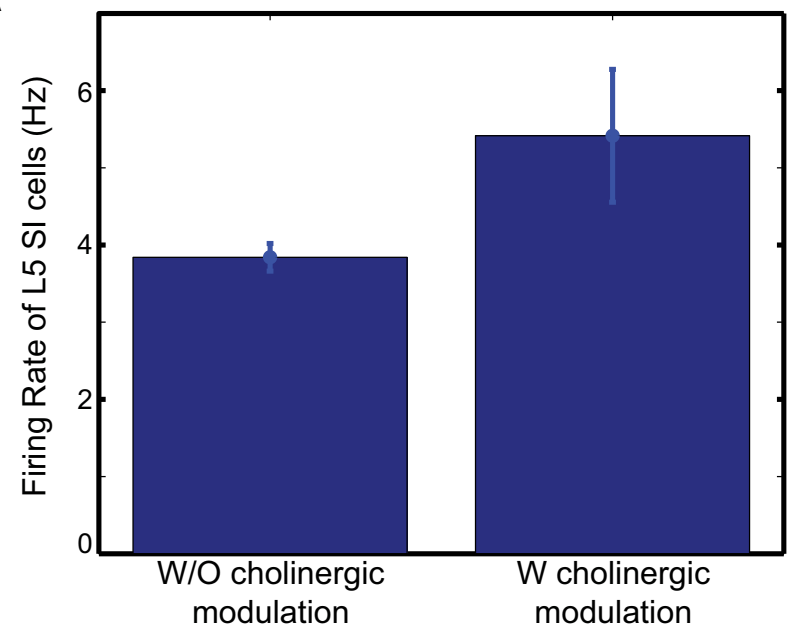

B

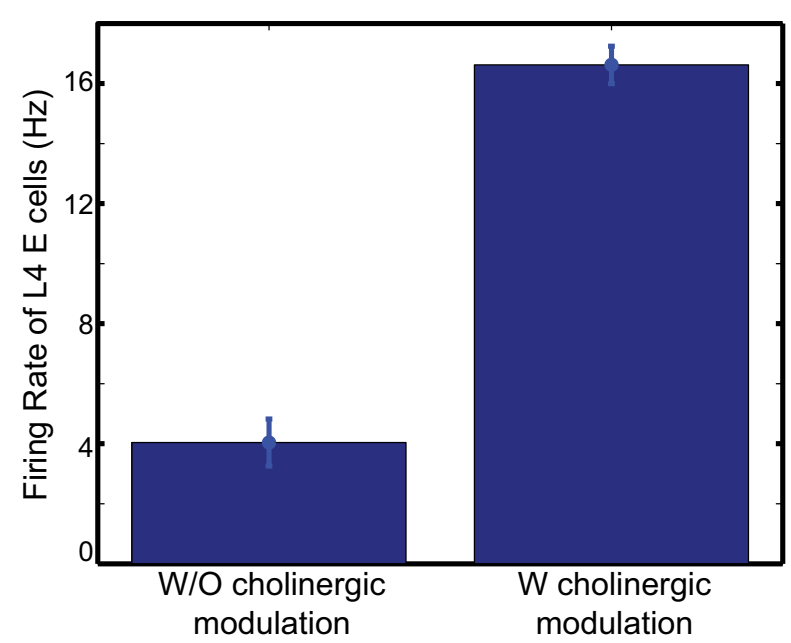

C

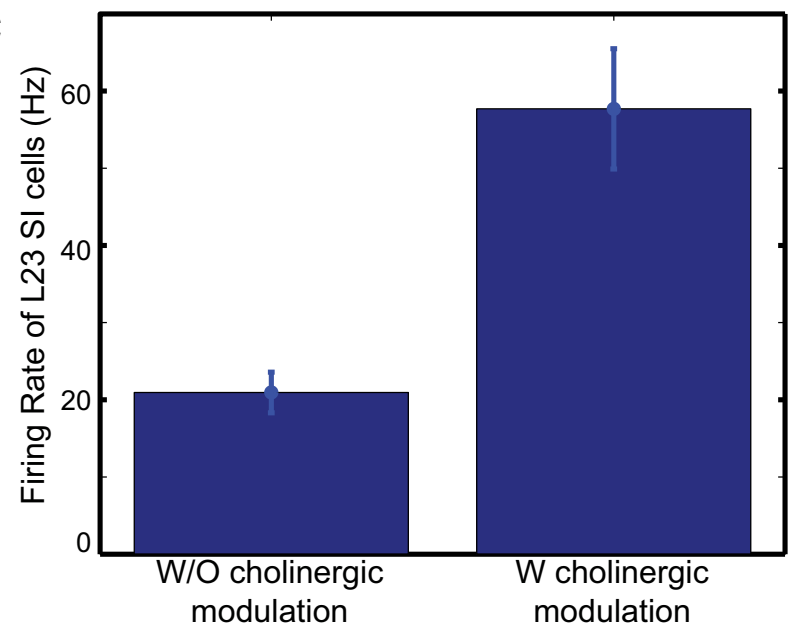

Figure 6. Effect of cholinergic modulation on A1 reflected on the spiking activity. All panels compare the firing rate of $A 1$ cells with and without cholinergic modulation. The effect of cholinergic modulation on the spiking activity of $L 5 \mathrm{SI}$ cells, $\mathrm{L} 4 \mathrm{E}$ cells, and L2/3 SI cells are shown in $A, B$, and $C$, respectively.

with reduced inhibition from FS to RS cells to determine whether FS cells can reduce RS cell activity. As expected, RS cell output power decreased as the inhibition from FS cells to RS cells increased (Fig. 9A). These results indicate that cholinergically induced deep layer beta rhythms allow L2/3 SI cells to enhance the spiking activity of L2/3 RS cells under the influence of inhibition from L2/3 FS cells stimulated by topdown gamma rhythms.

In our model, we consider cholinergic modulation mediated by both muscarinic and nicotinic receptors (see Materials and Methods). To better understand how they contribute to the cholinergic gating process discussed above, we perturbed each effect induced by cholinergic modulation and observed its impact on the dynamics of model A1. Kruglikov and Rudy (2008) found that muscarine application can reduce disynaptic inhibition onto pyramidal cells, which is modeled in L4 of A1. We restored the strength of inhibition from L4 FS to L4 E cells to represent the system without cholinergic modulation and to calculate the spectral power of L4 E cell outputs. Figure $9 B$ compares the power spectra averaged over 10 simulations with three different levels of inhibition from L4 FS to L4 E in A1. All (100\%) of the connection strength from L4 FS to L4 E cells corresponds to the default value used in simulations with cholinergic modulation. As seen in the figure, the peak frequency and amplitude shift to the lower frequencies and are reduced when inhibition strength increases, suggesting that muscarinic receptor-mediated effects enhance the $\mathrm{L} 4 \mathrm{E}$ cell responses to thalamic inputs directly in terms of both frequency and amplitude.

Xiang et al. (1998) found that L5 LTS cells were nicotinically depolarized and Arroyo et al. (2012) found that nicotinically activated non-FS cells project inhibition onto FS cells in L2/3. We tested such nicotinic-receptor-mediated effects by hyperpolarizing SI cells in L2/3 and L5 to represent systems without nicotinic modulation. Specifically, we compared the three different excitability levels (depolarization, midpoint, and hyperpolarization). For the "depolarization" and "hyperpolarization" conditions, we used the default values of applied currents $I_{a p p}$ in SI cells used for simulations with and without cholinergic modulation, respectively. For the "midpoint," $I_{a p p}$ was set to the mean values of the two default values. As shown in Figure $9 C$, the output powers of L2/3 RS cells between 45 and $60 \mathrm{~Hz}$, which are responsible for relaying bottom-up inputs, were reduced when we reduced the excitability of SI cells; the mean values and standard errors were obtained from 10 simulations.

Due to the pivotal role of L2/3 SI cells, we also evaluated the contribution of the M-current in L2/3 SI cells on gating and found that the M-current is reduced by cholinergic modulation. We increased the amount of M-current in L2/3 SI cells from the value associated with cholinergic modulation to determine whether this can modulate L2/3 RS cell activity. Figure 9D shows that the RS cell output between 45 and $60 \mathrm{~Hz}$ is negatively correlated to the amount of M-current in L2/3 SI cells; $100 \%$ of the $\mathrm{M}$-current in the figure is the default amount of M-current in L2/3 SI cells selected to simulate the presence of cholinergic modulation. That is, if the stronger bottom-up signaling is desirable, then the concentration of M-current in L2/3 SI cells should be reduced; if undesirable, it should be increased.

In brief, muscarinic effects can increase the responses of A1 to thalamic inputs directly and nicotinic effects can help L2/3 RS cells respond reliably to the ascending inputs from L4 E cells. These effects can enhance the intensity of bottom-up communication from A1 to Par2 in complementary ways.

\section{Implications of the cholinergic gating for the pathology of schizophrenia}

In the previous section, we saw that cholinergically activated L2/3 SI cells in A1 determine when A1 can project bottom-up signals to Par2, indicating that cholinergic modulation can control sen- 
sory outputs of A1 to Par2. This result may shed light on the pathology of abnormal rhythmic EEG signals found in patients with schizophrenia. Specifically, a $40 \mathrm{~Hz}$ auditory click sound can induce 40 $\mathrm{Hz}$ rhythmic activity in EEG signals; this induced $40 \mathrm{~Hz}$ rhythmic activity was smaller in patients and a prominent $20 \mathrm{~Hz}$ rhythmic activity also appeared (Kwon et al., 1999; Vierling-Claassen et al., 2008). Moreover, several studies (Martin et al., 2004; Martin and Freedman, 2007) suggested that nicotinic receptors, one of the targets of cholinergic modulation, can be associated with the pathology of schizophrenia.

Therefore, we hypothesize that the disrupted cholinergic modulation, which reduces L4 E cells' sensitivity to the external inputs, can account for the $20 \mathrm{~Hz}$ rhythmic activity induced by $40 \mathrm{~Hz}$ auditory click sounds because L4 E cells can skip cycles of $40 \mathrm{~Hz}$ inputs if they have lower sensitivity. To address this hypothesis, we provided $40 \mathrm{~Hz}$ synchronous inputs to L4 cells of A1 instead of Poisson trains. Individual auditory neurons in A1 can fire synchronously aligned to auditory click trains up to $40 \mathrm{~Hz}$ (Wang, 2007). Therefore, we assumed that a $40 \mathrm{~Hz}$ auditory click sound could induce $40 \mathrm{~Hz}$ synchronous thalamic outputs projecting to A1. We first determined the minimal strength of synchronous $40 \mathrm{~Hz}$ EPSCs to induce L4 E cells to fire reliably (Fig. 10A) and then repeated the simulation without cholinergic modulation (Fig. 10B). In our simulations, when cholinergic modulation was absent, L4 E cells tended to skip the next cycle after they successfully responded to one cycle of $40 \mathrm{~Hz}$ input, generating a significant difference ( $t$ test, $p<0.01)$ in spiking activity of L4 E cell activity (Fig. $10 C)$. We also calculated the mean value of power spectra of LFPs from 10 independent simulations. As seen in Figure $10 \mathrm{D}$, the $20 \mathrm{~Hz}$ peak is much bigger without cholinergic modulation, consistent with EEG abnormal activity in patients with schizophrenia (Kwon et al., 1999; Vierling-Claassen et al., 2008).

Vierling-Claassen et al. (2008) proposed that the prolonged GABA synaptic transmission may account for abnormal cortical rhythms (enhanced beta rhythms and reduced gamma rhythms) in patients with schizophrenia. Using a computational model, they showed that, if the decay time of inhibition from L4 FS cells increases, this will effectively enhance inhibition onto excitatory cells, thereby reducing gamma rhythms and enhancing beta rhythms. The mechanism discussed in Vierling-Claassen et al. (2008) is complementary to our model because both suggest that increased inhibition on excitatory cells (L4 E cells in our model) underlie the mechanisms of abnormal activity in response to $40 \mathrm{~Hz}$ auditory click trains.

G
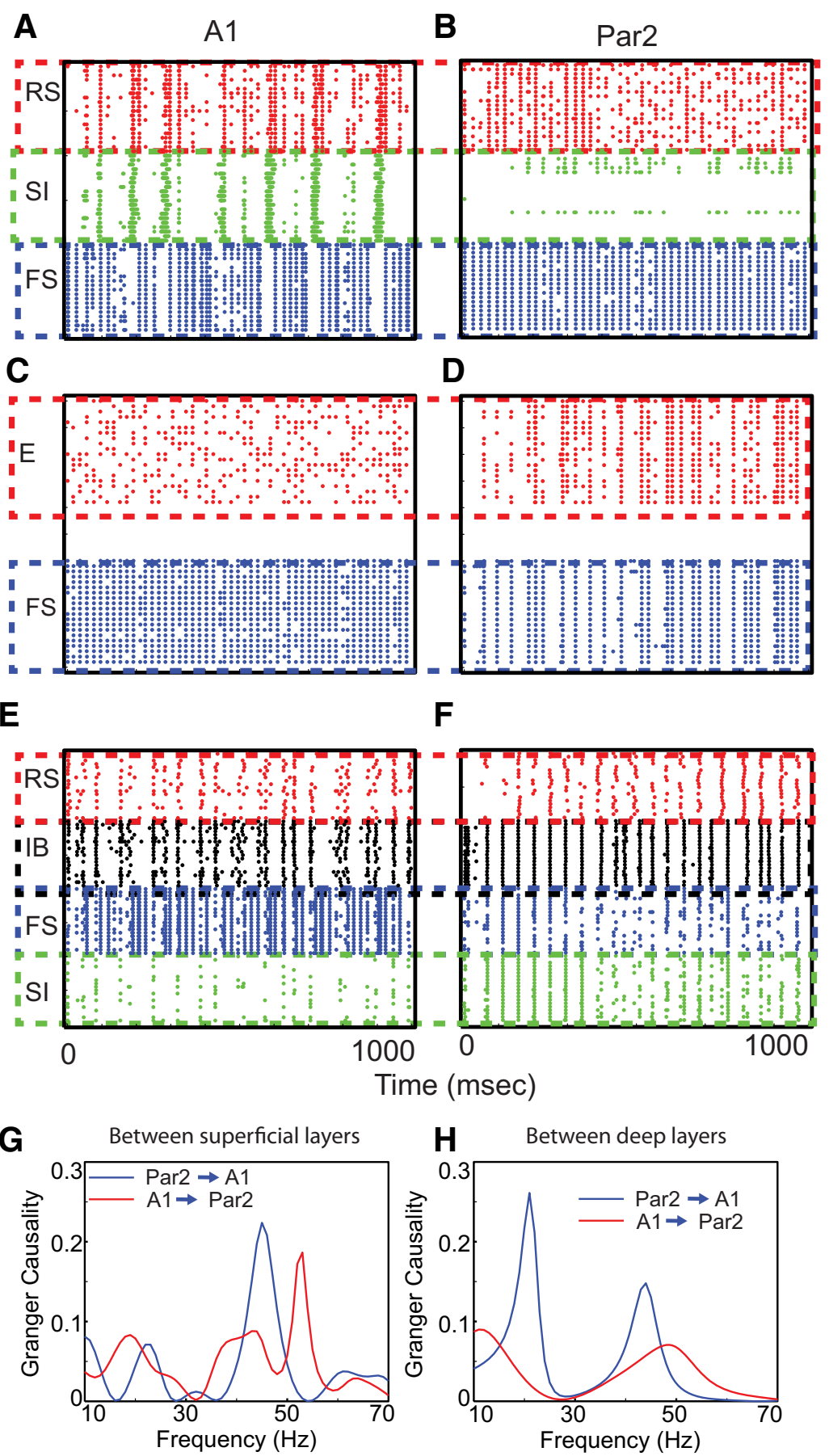

Figure 7. Cell activity of $A 1$ and Par2 with inter-areal connections in the presence of both kainate and cholinergic modulation. $\boldsymbol{A}, \boldsymbol{B}$, Superficial neural responses of $A 1$ and Par2 with synaptic connections between the two areas. $\boldsymbol{C}, \boldsymbol{D}$, and $\boldsymbol{E}, \boldsymbol{F}, \mathrm{L} 4$ and $L 5$ responses, respectively. $\mathbf{G}, \mathrm{GC}$ between superficial layer LFPs. $\boldsymbol{H}$, GC between deep layer LFPs.

\section{Discussion}

We used biophysical computational models to study potential mechanisms underlying temporal inter-areal interactions between A1 and Par2. Our simulation results suggest that the coordination between top-down gamma and beta rhythms is the key to the gating mechanisms capable of reproducing the causal interaction pattern observed experimentally (Roopun et al., 2010). Cholinergic modulation allows this coordination to occur.

Although our model is based on in vitro data, it can help us better understand in vivo signal processing. First, in our model, 
A

B

Between L2/3 RS cell acticity in A1 and L4 LFPs in A1
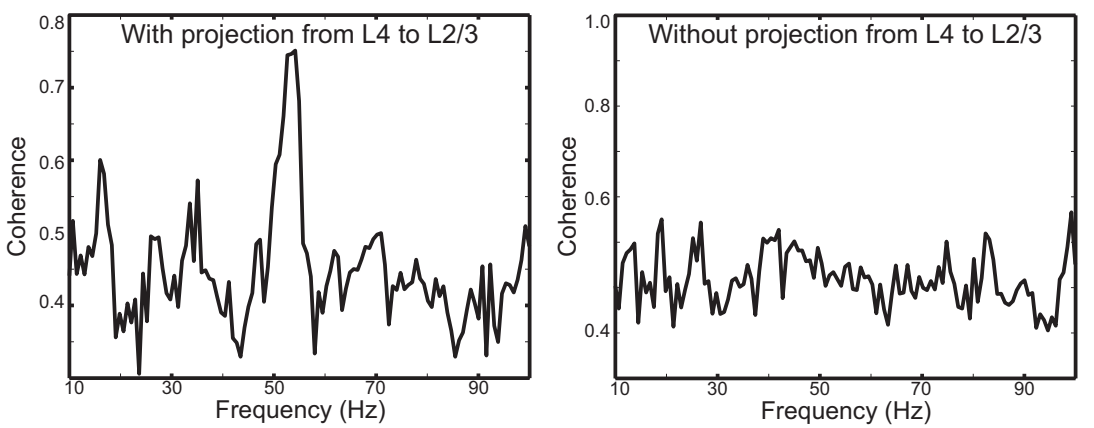

C

Between L2/3 FS cell acticity in A1 and L2/3 LFPs in Par2
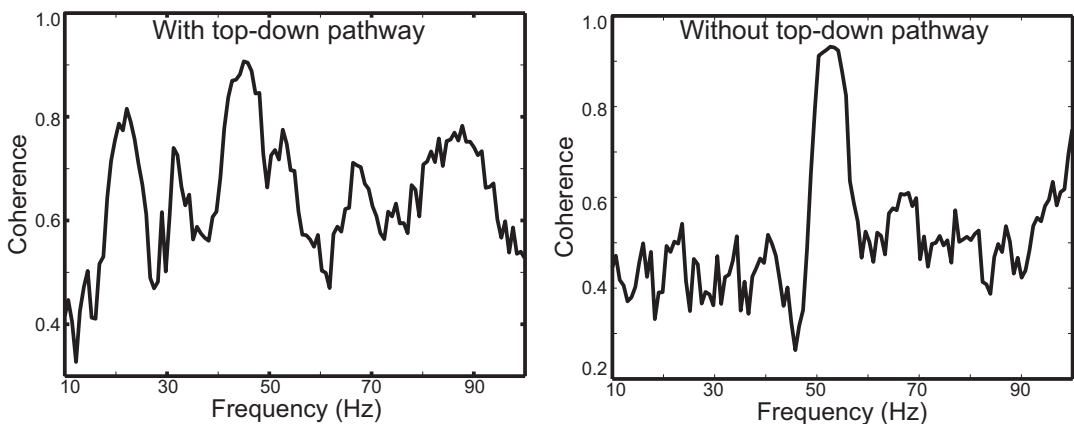

Figure 8. Inter-areal and inter-laminar communication reflected in the spike-field coherence. $A, B$, Spike-field coherence between $L 2 / 3$ RS cell-spiking activity in $A 1$ and granular layer LFPs in $A 1$ with and without ascending synaptic projection from $L 4$ to $L 2 / 3$. C, D, Spike-field coherence between L2/3 FS cell-spiking activity in A1 and superficial layer LFPs in Par2 with and without the top-down pathway.
A

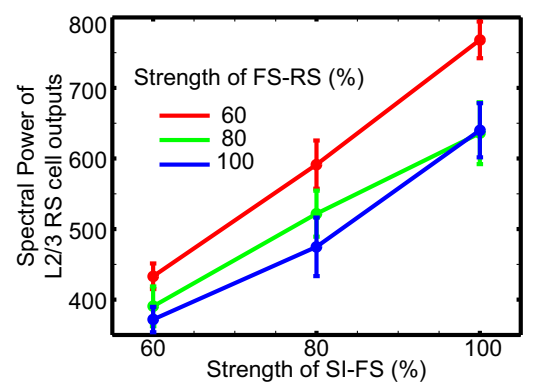

C

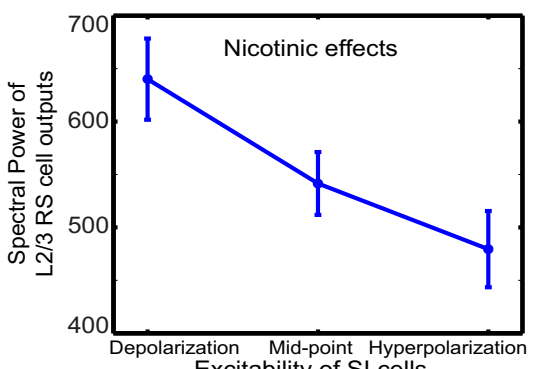

Excitability of SI cells
B

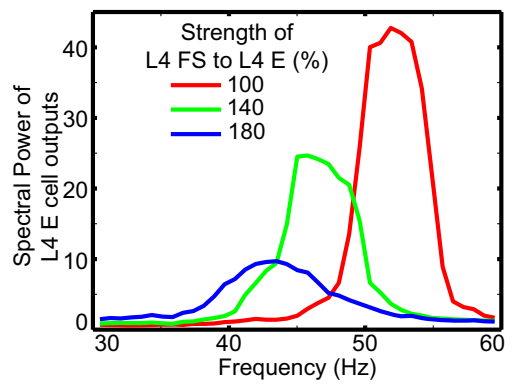

D

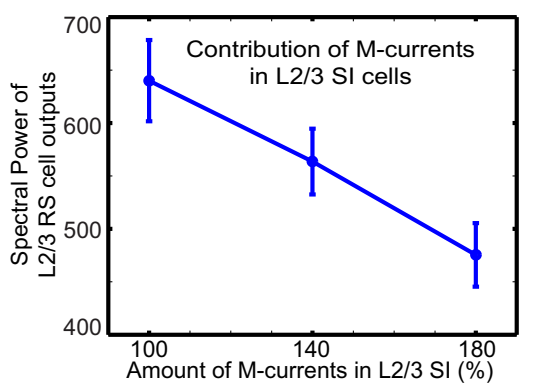

Figure 9. Cholinergic gating mechanism. $A$, Spectral power of L2/3RS cell-spiking activity depending on the connection strengths from FS to RS and from SI to FS cells, respectively. The $x$-axis shows the connection strength from SI to FS cells. Red, green, and blue lines show the results with $60 \%, 80 \%$, and $100 \%$ connection strength from $\mathrm{FS}$ to $\mathrm{RS}$ cells, respectively. $\boldsymbol{B}$, Average spectral power of $\mathrm{L} 4 \mathrm{E}$ cell activity depending on the connection strength from L4FS to $L 4 E$ cells. The numbers in the inset indicate relative strengths of the connection. $C, D$, Mean and SEs of spectral powers of L2/3 RS cell activity depending on the excitability of SI cells and the amount of M-currents in L2/3 SI cells, respectively. As before, 10 simulations are used for their calculations. The $x$-axes in $\boldsymbol{C}$ and $\boldsymbol{D}$ represent the applied current $\left(I_{\text {app }}\right)$ and the amount of M-current, respectively. stimulus-related gamma rhythms were enhanced by top-down beta rhythms, which is consistent with the "oscillatory hierarchy hypothesis" (Lakatos et al., 2005). Interestingly, top-down beta rhythms actually induce theta-like activity in L2/3 SI cells due to their M-current. This readily accounts for the positive correlation between gamma power and the phase of theta experimentally observed (Lakatos et al., 2005). Second, in our model, top-down beta rhythms can increase bottom-up gamma rhythms, which explains the enhancement of auditory gamma power during top-down process (Debener et al., 2003). Below, we discuss more implications of our model.

\section{Competition between top-down and bottom-up gamma rhythms may account for the diversity of attentional modulation of gamma rhythms}

Gamma rhythms were enhanced in V4 and reduced in V1 while monkeys participated in the same attentional task (Fries et al., 2001; Chalk et al., 2010). In our model, the top-down and bottom-up gamma rhythms, which target inhibitory and pyramidal cells, respectively, merge in the superficial layers. A recent modeling study (Jadi and Sejnowski, 2014) proposed that external synaptic inputs can increase or reduce gamma power depending on their major targets. When inputs to excitatory cells are enhanced, gamma power increases. In contrast, gamma power decreases when inputs to inhibitory cells are enhanced. Together, one can derive a potential scenario: gamma power can increase (Fries et al., 2001) when bottom-up gamma rhythms targeting excitatory RS cells become dominant during attentional processing. Similarly, it can decrease (Chalk et al., 2010) or stay at the same level (Bauer et al., 2012) depending on the competition between top-down and bottom-up gamma rhythms. The difference in the balance of top-down and bottom-up signaling between V1 and V4 may be explained by the size of receptive fields or cell assemblies in the two regions (Freeman and Simoncelli, 2011); the small receptive field in V1 may have additional local impact on the gamma rhythms (Börgers et al., 2012).

\section{Gamma rhythms may have multiple} functions in inter-areal communication In our model, top-down gamma rhythms induce a blockade of sensory signals, a function distinct from the traditional notion that gamma rhythms convey sensory signals to the higher-order cognitive areas 
A

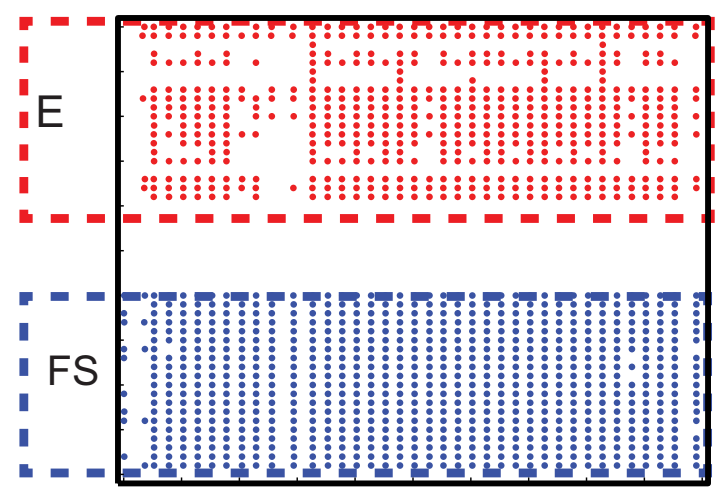

B

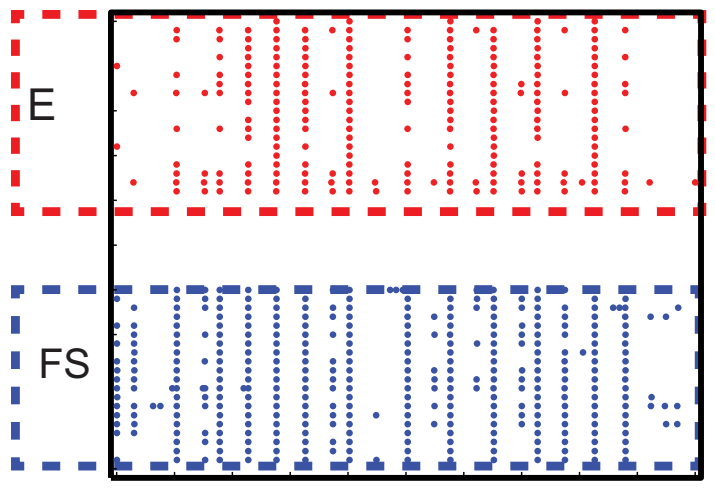

C

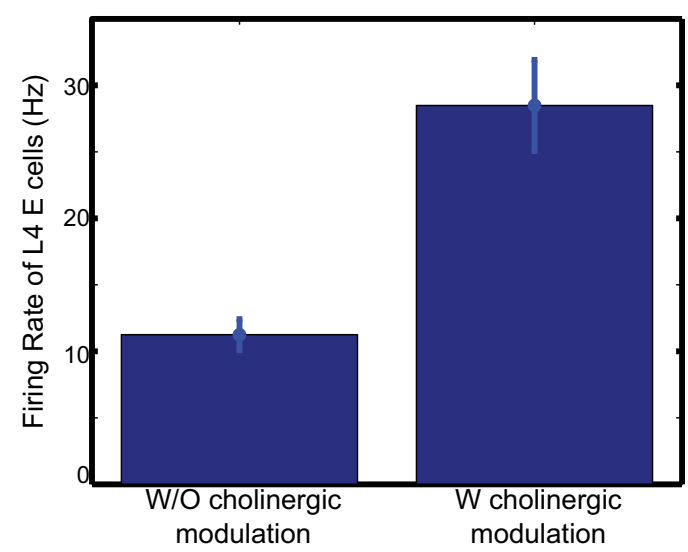

D

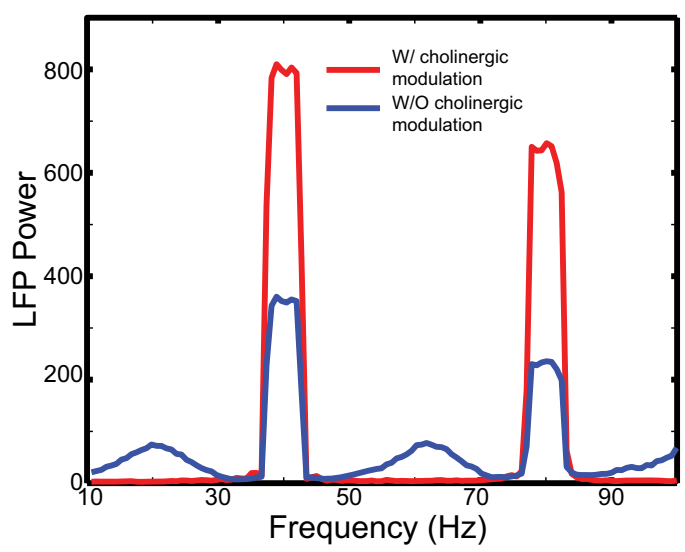

Figure 10. Effect of cholinergic modulation on the sensitivity of $L 4 \mathrm{E}$ cells in response to synchronous external inputs. $A, B, L 4$ cell activity of $A 1$ in response to $40 \mathrm{~Hz}$ synchronous trains of EPSCS to L4 E and FS cells with and without cholinergic modulation, respectively. C, Spiking activity of $L 4 E$ cells with and without cholinergic modulation. D, Power spectra of L4 LFPs.
(Singer and Gray, 1995; Fries, 2005). This newly proposed function does not exclude the traditional view. Instead, it suggests that gamma rhythms may subserve different functions depending on the hierarchical direction of information flow. Indeed, the bottom-up signals from A1 to Par2 in our model are also mediated by gamma rhythms (see dual peaks in the gamma bands in Fig. $7 G$ ). An interesting parallel has been shown for interactions between the hippocampus and medial prefrontal cortex (mPFC) (Peyrache et al., 2011). Specifically, spindles targeting cortical FS cells were capable of making mPFC cortex unresponsive to monosynaptic inputs from the hippocampus. Moreover, the spectral power in the gamma-frequency band was found to be modulated by spindles during the encoding process, indicating that gamma rhythms may also be involved in this observed signal blockade process.

\section{Disrupted cholinergic network can account for some of the abnormal EEG activity in people with schizophrenia} Abnormal gamma and beta rhythms have been found in patients with schizophrenia (Spencer et al., 2004; Flynn et al., 2008; Vierling-Claassen et al., 2008) and disrupted cholinergic neuromodulation may also play a role in generating the cognitive deficits associated with this syndrome (for review, see Haydar and Dunlop, 2010). Our simulations suggest at least three potential links between this abnormal rhythmic activity and disrupted cholinergic neuromodulation. First, in our model, the cholinergic modulation increases beta rhythms in the deep layers, thereby increasing gamma rhythms in granular and superficial layers. This means that a disrupted cholinergic network can reduce stimulus-evoked gamma rhythms. Second, without cholinergic modulation, L4 E cells cannot reliably respond to $40 \mathrm{~Hz}$-auditory click trains (Fig. 10); instead, they generate $20 \mathrm{~Hz}$ rhythmic activity, consistent with the reported abnormal rhythmic activity (Kwon et al., 1999; Vierling-Claassen et al., 2008). Third, in our model, cholinergic modulation can regulate FS cell activity induced by top-down gamma rhythms by activating L2/3 SI cells inhibiting L2/3 FS cells. Conversely, with disrupted cholinergic modulation, SI cells cannot suppress FS cell activity, so L2/3 RS cells will be less sensitive to sensory signals. This scenario could help to explain the disrupted perception in patients with schizophrenia (Spencer et al., 2004; Lewis et al., 2005; Butler et al., 2008).

Tonic release of cholinergic modulation can alter cortical cells to be sensitive to external inputs

Cholinergic drive is thought to be associated with filtering and attentional processing (Thiele, 2013). Our simulation results provide some insights on its functions.

First, we considered the muscarinic effects in $\mathrm{L} 4$ of $\mathrm{Al}$, which made bottom-up gamma rhythms faster and stronger (Fig. 9B). That is, the responses of $\mathrm{L} 4$ to thalamic inputs became stronger in the presence of cholinergic modulation, which is consistent with significant effects of a muscarinic receptor blocker in behavioral performance (Herrero et al., 2008). This increased neural activity may not fit into the hypothesis that muscarinic signaling enhances filtering processes (Thiele, 2013). Specifically, our simulation results are consistent with the notion that cholinergic modulation is associated with attentional processing, but they also indicate that effective filtering may also be provided by topdown gamma rhythms that increase FS cell activity in L2/3.

Second, the A1 beta rhythms induced by top-down signaling can disinhibit L4 E and L2/3 RS cells by inhibiting FS cells in both layers. This disinhibition allows L2/3 RS cells to respond reliably 
to thalamic inputs. Deep-layer beta rhythms were abolished by a nicotinic receptor antagonist (Roopun et al., 2010) and deep layer LTS cells, modeled here with SI cells, were depolarized by a nicotinic agonist (Xiang et al., 1998), suggesting that nicotinic signaling can be associated with the modulatory control of the intensity of bottom-up communication: Our simulation results suggest that the enhanced excitability of SI cells (Fig. 9C) can enhance bottom-up communication indirectly.

Because we assume that cholinergic modulation is present over the entire simulation period, our results are related to the tonic release of acetylcholine, one of the two modes reported in Parikh et al. (2007). The cholinergic gating in our model makes A1 more responsive to bottom-up signaling, which is consistent with the hypothesis that tonic acetylcholine release is associated with attentional orienting demanding increased sensitivity to external stimuli (Parikh et al., 2007).

\section{Conclusions}

Cholinergic gating may broadly influence cortical communication. The focus of the present model was on interactions between primary auditory cortex and a higher-order, anatomical neighbor because, at present, sufficient synaptic and cellular data are only available to constrain a model of these pairs biologically. However, there is evidence that the cholinergic gating mechanisms proposed here may generalize to other inter-areal interactions. Further up the hierarchical cortical stream, Buschman and Miller (2007) found that the coherence between frontal and parietal areas is increased in the gamma-frequency band and (high) beta-frequency band during bottom-up and top-down processing, respectively, in a task requiring attention. The pattern of dynamical interactions described in the present work may also be found in different sensory modalities: Bastos et al. (2015) demonstrated how top-down beta rhythms and bottom-up gamma rhythms may be used across visual cortical hierarchies and Gregoriou et al. (2009) found enhanced coherence between FEF and $\mathrm{V} 4$ in the gamma-frequency band during task performance.

These simulations demonstrate that cholinergic neuromodulation-acting via two subtypes of receptor-can have multiple network effects relevant to sensory processing. Enhanced responsiveness of primary sensory input layer 4 can occur directly or under the control of higher-order cortices via top-down beta rhythms. In addition, we show a relatively novel effect of topdown gamma rhythms in potentially enhancing the selectivity of superficial layers of primary sensory cortex by inhibiting the input from undesired sensory sources. The simulations predict that both of these top-down processes may work in concert to ensure appropriate cortical filtering during enhanced primary representation of input in attention-related tasks. This balance of sensitivity and selectivity appears to manifest as a network analog of gain control in single neocortical neurons (Bosman et al., 2012; Reynolds and Chelazzi, 2004) and we suggest that its failure may underlie some of the cognitive deficits seen in patients with schizophrenia.

\section{References}

Ainsworth M, Lee S, Cunningham MO, Roopun AK, Traub RD, Kopell NJ, Whittington MA (2011) Dual gamma rhythm generators control interlaminar synchrony in auditory cortex. J Neurosci 31:17040-17051. CrossRef Medline

Akam TE, Kullmann DM (2012) Efficient "communication through coherence" requires oscillations structured to minimize interference between signals. PLoS Comput Biol 8:e1002760. CrossRef Medline

Arroyo S, Bennett C, Aziz D, Brown SP, Hestrin S (2012) Prolonged disynaptic inhibition in the cortex mediated by slow, Non- 7 nicotinic excita- tion of a specific subset of cortical interneurons. J Neurosci 32: 3859-3864. CrossRef Medline

Bastos AM, Vezoli J, Bosman CA, Schoffelen J-M, Oostenveld R, Dowdall JR, ... Fries P (2015) Visual areas exert feedforward and feedback influences through distinct frequency channels. Neuron 390-401.

Bauer M, Kluge C, Bach D, Bradbury D, Heinze HJ, Dolan, RJ, Driver J (2012) Cholinergic enhancement of visual attention and neural oscillations in the human brain. Curr Biol 22:397-402. CrossRef Medline

Börgers C, Kopell N (2005) Effects of noisy drive on rhythms in networks of excitatory and inhibitory neurons. Neural Comput 17:557-608. CrossRef Medline

Börgers C, Kopell NJ (2008) Gamma oscillations and stimulus selection. Neural Comput 20:383-414. CrossRef Medline

Börgers C, Franzesi G, LeBeau FEN, Boyden EE, Kopell NJ (2012) Minimal size of cell assemblies coordinated by gamma oscillations. PLoS Comput Biol 8:e1002362. CrossRef Medline

Bosman CA, Schoffelen JM, Brunet N, Oostenveld R, Bastos AM, Womelsdorf T, Rubehn B, Stieglitz T, De Weerd P, Fries P (2012) Attentional stimulus selection through selective synchronization between monkey visual areas. Neuron 75:875-888. CrossRef Medline

Buschman TJ, Miller EK (2007) Top-down versus bottom-up control of attention in the prefrontal and posterior parietal cortices. Science 315: 1860-1862. CrossRef Medline

Butler PD, Silverstein SM, Dakin SC (2008) Visual perception and its impairment in schizophrenia. Biol Psychiatry 64:40-47. CrossRef Medline

Chalk M, Herrero JL, Gieselmann MA, Delicato LS, Gotthardt S, Thiele A (2010) Attention reduces stimulus-driven gamma frequency oscillations and spike field coherence in V1. Neuron 66:114-125. CrossRef Medline

Debener S, Herrmann CS, Kranczioch C, Gembris D, Engel AK (2003) Topdown attentional processing enhances auditory evoked gamma band activity. Neuroreport 14:683-686. CrossRef Medline

Destexhe A, Mainen ZF, Sejnowski TJ (1994) Synthesis of models for excitable membranes, synaptic transmission and neuromodulation using a common kinetic formalism. J Comput Neurosci 1:195-230. CrossRef Medline

Donner TH, Siegel M, Fries P, Engel AK (2009) Buildup of choicepredictive activity in human motor cortex during perceptual decision making. Curr Biol 19:1581-1585. CrossRef Medline

Felleman DJ, Van Essen DC (1991) Distributed hierarchical processing in the primate cerebral cortex. Cereb Cortex 1:1-47. Medline

Flynn G, Alexander D, Harris A, Whitford T, Wong W, Galletly C, Silverstein S, Gordon E, Williams LM (2008) Increased absolute magnitude of gamma synchrony in first-episode psychosis. Shizophr Res 105:262-271. CrossRef Medline

Freeman J, Simoncelli, EP (2011) Metamers of the ventral stream. Nat Neurosci 14:1195-1201. CrossRef Medline

Fries P (2005) A mechanism for cognitive dynamics: neuronal communication through neuronal coherence. Trends Cogn Sci 9:474-480. CrossRef Medline

Fries P (2009) Neuronal gamma-band synchronization as a fundamental process in cortical computation. Annu Rev Neurosci 32:209-224. CrossRef Medline

Fries P, Reynolds JH, Rorie AE, Desimone R (2001) Modulation of oscillatory neuronal synchronization by selective visual attention. Science 291: 1560-1563. CrossRef Medline

Ghitza O (2012) On the role of theta-driven syllabic parsing in decoding speech: Intelligibility of speech with a manipulated modulation spectrum. Front Psychol 3:238. Medline

Gibson JR, Beierlein M, Connors BW (1999) Two networks of electrically coupled inhibitory neurons in neocortex. Nature 402:75-79. CrossRef Medline

Gregoriou GG, Gotts SJ, Zhou H, Desimone R (2009) visual cortex during attention. Science 324:1207-1210. Medline

Gulledge AT, Park SB, Kawaguchi Y, Stuart GJ (2007) Heterogeneity of phasic cholinergic signaling in neocortical neurons. J Neurophysiol 97:22152229. CrossRef Medline

Haydar SN, Dunlop J (2010) Neuronal nicotinic acetylcholine receptorstargets for the development of drugs to treat cognitive impairment associated with schizophrenia and Alzheimer's disease. Curr Top Med Chem 10:144-152. CrossRef Medline

Herrero JL, Roberts MJ, Delicato LS, Gieselmann MA, Dayan P, Thiele A 
(2008) Acetylcholine contributes through muscarinic receptors to attentional modulation in V1. Nature 454:1110-1114. CrossRef Medline

Jadi MP, Sejnowski TJ (2014) Cortical oscillations arise from contextual interactions that regulate sparse coding. Proc Natl Acad Sci U S A 111: 6780-6785. CrossRef Medline

Kramer MA, Roopun AK, Carracedo LM, Traub RD, Whittington MA, Kopell NJ (2008) Rhythm generation through period concatenation in rat somatosensory cortex. PLoS Comput Biol 4:e1000169. CrossRef Medline

Kruglikov I, Rudy B (2008) Perisomatic GABA release and thalamocortical integration onto neocortical excitatory cells are regulated by neuromodulators. Neuron 58:911-924. CrossRef Medline

Kwon JS, O'Donnell BF, Wallenstein GV, Greene RW, Hirayasu Y, Nestor PG, Hasselmo ME, Potts GF, Shenton ME, McCarley RW (1999) Gamma frequency-range abnormalities to auditory stimulation in schizophrenia. Arch Gen Psychiatry 56:1001-1005. CrossRef Medline

Lakatos P, Shah AS, Knuth KH, Ulbert I, Karmos G, Schroeder CE (2005) An oscillatory hierarchy controlling neuronal excitability and stimulus processing in the auditory cortex. J Neurophysiol 94:1904-1911. CrossRef Medline

Lee JH, Whittington MA, Kopell NJ (2013) Top-down beta rhythms support selective attention via inter-laminar interaction: a model. PLoS Comput Biol 9:e1003164. CrossRef Medline

Levy RB, Reyes AD, Aoki C (2008) Cholinergic modulation of local pyramid-interneuron synapses exhibiting divergent short-term dynamics in rat sensory cortex. Brain Res 1215:97-104. CrossRef Medline

Lewis DA, Hashimoto T, Volk DW (2005) Cortical inhibitory neurons and schizophrenia. Nat Rev Neurosci 6:312-324. CrossRef Medline

Markov NT, Kennedy H (2013) The importance of being hierarchical. Curr Opin Neurobiol 23:187-194. CrossRef Medline

Martin LF1, Kem WR, Freedman R (2004) Alpha-7 nicotinic receptor agonist: potential new candidates for the treatment of schizophrenia. Psychopharmacology (Berl) 174:54-64. Medline

Martin LF, Freedman R (2007) Schizophrenia and the alpha7 nicotinic acetylcholine receptor. Int Rev Neurobiol 78:225-246. CrossRef Medline

Mazzoni A, Panzeri S, Logothetis NK, Brunel N (2008) Encoding of naturalistic stimuli by local field potential spectra in networks of excitatory and inhibitory neurons. PLoS Comput Biol 4:e1000239. CrossRef Medline

Meltzer JA, Zaveri HP, Goncharova II, Distasio MM, Papademetris X, Spencer SS, Spencer DD, Constable RT (2008) Effects of working memory load on oscillatory power in human intracranial EEG. Cereb Cortex 18: 1843-1855. CrossRef Medline

Mitchell JF, Sundberg KA, Reynolds JH (2007) Differential attentiondependent response modulation across cell classes in macaque visual area V4. Neuron 55:131-141. CrossRef Medline

Mitra P, Bokil H (2007) Observed brain dynamics. New York: Oxford UP.

Otsuka T, Kawaguchi Y (2009) Cortical inhibitory cell types differentially form intralaminar and inter-laminar subnetworks with excitatory neurons. J Neurosci 29:10533-10540. CrossRef Medline

Parikh V, Kozak R, Martinez V, Sarter M (2007) Prefrontal acetylcholine release controls cue detection on multiple timescales. Neuron 56:141154. CrossRef Medline

Pesaran B, Nelson MJ, Andersen RA (2008) Free choice activates a decision circuit between frontal and parietal cortex. Nature 453:406-409. CrossRef Medline
Peyrache A, Battaglia FP, Destexhe A (2011) Inhibition recruitment in prefrontal cortex during sleep spindles and gating of hippocampal inputs. Proc Natl Acad Sci U S A 108:17207-17212. CrossRef Medline

Reynolds JH, Chelazzi L (2004) Attentional modulation of visual processing. Annu Rev Neurosci 27:611-647. CrossRef Medline

Roopun AK, Middleton SJ, Cunningham MO, LeBeau FE, Bibbig A, Whittington MA, Traub RD (2006) A beta2-frequency $(20-30 \mathrm{~Hz})$ oscillation in nonsynaptic networks of somatosensory cortex. Proc Natl Acad Sci U S A 103:15646-15650. CrossRef Medline

Roopun AK, Lebeau FE, Rammell J, Cunningham MO, Traub RD, Whittington MA (2010) Cholinergic neuromodulation controls directed temporal communication in neocortex in vitro. Front Neural Circuits 4:8. Medline

Saalmann YB, Pigarev IN, Vidyasagar TR (2007) Neural mechanisms of visual attention: how top-down feedback highlights relevant locations. Science 316:1612-1615. CrossRef Medline

Saalmann YB, Pinsk MA, Wang L, Li X, Kastner S (2012) The pulvinar regulates information transmission between cortical areas based on attention demands. Science 337:753-756. CrossRef Medline

Seth AK (2010) A MATLAB toolbox for Granger causal connectivity analysis. J Neurosci Methods 186:262-273. CrossRef Medline

Silberberg G, Markram H (2007) Disynaptic inhibition between neocortical pyramidal cells mediated by Martinotti cells. Neuron 53:735-746. CrossRef Medline

Singer W, Gray CM (1995) Visual feature integration and the temporal correlation hypothesis. Annu Rev Neurosci 18:555-586. CrossRef Medline

Spencer KM, Nestor PG, Perlmutter R, Niznikiewicz MA, Klump MC, Frumin M, Shenton ME, McCarley RW (2004) Neural synchrony indexes disordered perception and cognition in schizophrenia. Proc Natl Acad Sci U S A 101:17288-17293. CrossRef Medline

Thiele A (2013) Muscarinic signaling in the brain. Annu Rev Neurosci 36: 271-294. CrossRef Medline

Thomson AM, West DC, Hahn J, Deuchars J (1996) IPSPs elicited in pyramidal cells by three classes of interneurones in slices of rat neocortex. J Physiol 496:81-102. Medline

Traub RD, Bibbig A, LeBeau FE, Cunningham MO, Whittington MA (2005) Persistent gamma oscillations in superficial layers of rat auditory neocortex: experiment and model. J Physiol 562:3-8. CrossRef Medline

Vierling-Claassen D, Siekmeier P, Stufflebeam S, Kopell N (2008) Modeling GABA alterations in schizophrenia: a link between impaired inhibition and altered gamma and beta range auditory entrainment. J Neurophysiol 99:2656-2671. CrossRef Medline

Wang X (2007) Neural coding strategies in auditory cortex. Hear Res 229: 81-93. CrossRef Medline

Wang XJ (2010) Neurophysiological and computational principles of cortical rhythms in cognition. Physiol Rev 90:1195-1268. CrossRef Medline

Whittington MA, Traub RD, Kopell N, Ermentrout B, Buhl EH (2000) Inhibition-based rhythms: experimental and mathematical observations on network dynamics. Int J Psychophysiol 38:315-336. CrossRef Medline

Womelsdorf T, Schoffelen JM, Oostenveld R, Singer W, Desimone R, Engel AK, Fries P (2007) Modulation of neuronal interactions through neuronal synchronization. Science 316:1609-1612. CrossRef Medline

Xiang Z, Huguenard JR, Prince DA (1998) Cholinergic switching within neocortical inhibitory networks. Science 281:985-988. CrossRef Medline 